\title{
Title: Comparative efficacy and safety of pharmacological interventions for the treatment of COVID-19: A systematic review and network meta-analysis of confounder-adjusted 20212 hospitalized patients
}

Min Seo Kim, $\mathrm{MD}^{1,4^{*} \dagger}$, Min Ho An, $\mathrm{MD}^{2,5^{*}}$, Won Jun Kim, MD ${ }^{1,7}$, Tae-Ho Hwang, DSS, $\mathrm{PhD}^{3,6 \dagger}$

*These authors contributed equally to this work.

${ }^{\dagger}$ Co-corresponding authors

${ }^{1}$ Korea University, College of Medicine, Seoul, Republic of Korea

${ }^{2}$ Ajou University, School of Medicine, Suwon, Republic of Korea

${ }^{3}$ Department of pharmacology, Pusan National University, School of Medicine, Yangsan, Republic of Korea

${ }^{4}$ Cheongsan Public Health Center, Wando, Republic of Korea.

${ }^{5}$ So Ahn Public Health Center, Wando, Republic of Korea.

${ }^{6}$ Gene and Cell Therapy Research Center for Vessel-associated Diseases, School of Medicine, Pusan National University, Yangsan, Republic of Korea

${ }^{7}$ Gangneung Prison Medical Department, Ministry of Justice, Republic of Korea.

\section{Corresponding authors:}

Min Seo Kim, MD

Korea University, College of Medicine

Director of Cheongsan Public Health Center, Ministry of Health and Welfare, Wando, Republic of Korea

Phone: +82-10-8864-9938

Email: minseolike@naver.com 
Tae-Ho Hwang, DSS, PhD.

Department of pharmacology, Pusan National University, School of Medicine, Yangsan, Republic of Korea

Director of Gene and Cell Therapy Research Center for Vessel-associated Diseases, School of Medicine, Pusan National University, Yangsan, Republic of Korea

Phone: +82-10-71579950

Keywords: COVID-19, Hydroxychloroquine, Remdesivir, tocilizumab, anakinra, corticosteroid, antiviral, mortality, viral clearance, network meta-analysis

Category: Systematic review and network meta-analysis

Total word count: 3531

Number of figures: 5

Number of tables: 2

Number of supplementary figures and tables: 1

This manuscript has been reviewed and is approved by all authors.

Min Seo Kim, Min Ho An, Won Jun Kim, Tae-Ho Hwang have no commercial associations that may present a conflict of interest in relation to this manuscript. 


\section{Summary Box}

\section{Section 1: What is already known on this topic}

- Numerous clinical trials and observational studies have investigated various pharmacological agents as potential treatment for COVID-19.

- Results from numerous studies are heterogeneous and sometimes even contradictory to one another, making it difficult for clinicians to determine which treatments are truly effective.

- Level of evidence behind each outcome from diverse studies remains unknown.

\section{Section 2: What this study adds}

- Anti-inflammatory agents (tocilizumab, anakinra, and IVIG) and remdesivir may safely and effectively improve clinical outcomes of COVID-19.

- Widely used hydroxychloroquine provides marginal clinical benefit in improving viral clearance rates whilst posing both cardiac and non-cardiac safety risks.

- Only 20\% of current evidence on pharmacological management of COVID-19 is on moderate/high evidence certainty and can be considered in practice and policy; remaining $80 \%$ are of low or very low certainty and warrant further studies to establish firm conclusions. 


\begin{abstract}
Objective: To evaluate the comparative efficacy and safety of pharmacological interventions used in treating COVID-19 and form a basis for an evidence-based guideline of COVID-19 management by evaluating the level of evidence behind each treatment regimen in different clinical settings.
\end{abstract}

Design: Systematic review and network meta-analysis

Data Sources: PubMed, Google Scholar, MEDLINE, the Cochrane Library, medRxiv, SSRN, WHO International Clinical Trials Registry Platform, and ClinicalTrials.gov up to June $9^{\text {th }}$, 2020 .

Study Selection: Published and unpublished randomized controlled trials (RCTs) and baseline-adjusted observational studies which met our predefined eligibility criteria.

Main Outcome Measures: The outcomes of interest were mortality, progression to severe disease (severe pneumonia or admission to intensive care unit (ICU)), time to viral clearance, QT prolongation, fatal cardiac complications, and non-cardiac serious adverse events. The level of evidence behind each outcome was also measured using the Grading of Recommendations Assessment, Development, and Evaluation (GRADE) framework.

Results: 49 studies with a total of 20212 confounder-adjusted patients were included for analysis. The risk of progression to severe pneumonia or ICU admission was significantly reduced with tocilizumab (GRADE low), anakinra (GRADE very low), and remdesivir (GRADE high) compared to standard care. Tocilizumab was shown to reduce mortality rate for both moderate-severe patients in the non-ICU setting at admission (Odds ratio (OR) 0.31, 95\% confidence interval (CI) 0.18 to 0.54 , GRADE low) and critically ill patients in the ICU setting (OR $0.67,95 \%$ CI 0.50 to 0.91 , GRADE low). High dose IVIG reduced death rate (GRADE low) while corticosteroids increased mortality for critically ill patients (GRADE moderate). Convalescent plasma and hydroxychloroquine were shown to promote viral clearance (OR 11.39, 95\% CI 3.91 to 33.18, GRADE low and OR 6.08, 95\% CI 2.74 to 13.48 , GRADE moderate, respectively) while not altering mortality or progression to the severe courses. The combination of hydroxychloroquine and azithromycin was shown to be associated with increased QT prolongation incidence (OR 1,85, 95\% CI 1.05 to 3.26, GRADE low) and fatal cardiac complications in cardiac-impaired populations (OR 2.26, 95\% CI 1.26 to 4.05, GRADE low). High-dose (>600mg/day) hydroxychloroquine monotherapy was significantly associated with increased non-cardiac serious adverse events (GRADE moderate).

Conclusion: Anti-inflammatory agents (tocilizumab, anakinra, and IVIG) and remdesivir 
medRxiv preprint doi: https://doi.org/10.1101/2020.06.15.20132407; this version posted June 19, 2020. The copyright holder for this preprint (which was not certified by peer review) is the author/funder, who has granted medRxiv a license to display the preprint in perpetuity.

\section{It is made available under a CC-BY-NC-ND 4.0 International license .}

may safely and effectively improve outcomes of hospitalized COVID-19 patients. Widely used hydroxychloroquine provides marginal clinical benefit in improving viral clearance rates whilst posing both cardiac and non-cardiac safety risks, especially in the vulnerable population. Only $20 \%$ of current evidence on pharmacological management of COVID-19 is on moderate and high evidence certainty and can be considered in practice and policy; remaining $80 \%$ are of low or very low certainty and warrant further studies to establish firm conclusions.

Systematic Review Registration: PROSPERO 2020: CRD42020186527. 


\section{Introduction}

A large registry-based study investigating the effect of hydroxychloroquine on COVID-19 patients reported surprisingly high mortality rate and ventricular arrhythmia incidence with hydroxychloroquine use ${ }^{1}$, and this paper contributed to the decision of the World Health Organization (WHO) to pause all ongoing trials on hydroxychloroquine due to safety concerns. Although this paper was retracted after concerns raised by clinicians and scientists, the delay of trials and confusion caused by the paper were unavoidable. This was an alarming event that due to the sudden advent of COVID-19 and global urgency to find treatments, many clinical and observational studies are of suboptimal quality ${ }^{2}$; therefore, it may be unreliable to make decisions grounded on the evidence of a single paper. Prospective metaanalyses synthesizing multiple studies using predefined eligibility criteria can be an interim solution to generate reliable conclusions ${ }^{2}$ and protect from ill-informed changes in practice and policy.

Numerous COVID-19 clinical trials are underway, and over 31 pharmacological agents and combinations have been investigated as potential treatments of COVID-19 to date. Network meta-analysis (NMA) is an analytical tool that enables the a single coherent ranking of such numerous interventions, and it can thus aid decision-makers who must choose amongst an array of treatment options ${ }^{3}$.

We conducted the first network meta-analysis with selective predefined eligibility criteria for both published and unpublished data, and investigated 31 treatment regimens for comparative efficacy and safety. We incorporated 49 studies (16 randomized controlled trials (RCT) and 33 baseline-adjusted observational studies) including a total of 20212 confounder-adjusted patients. The level of certainty behind the evidence for each outcome was evaluated to assist the decision-making of clinicians and policy makers. This study will serve as the basis for an individual patient data (IPD) network meta-analysis that we are designing as a future study.

\section{Methods}

\section{Search strategy and selection criteria}

We searched PubMed, Google Scholar, MEDLINE, the Cochrane Library, medRxiv, SSRN, WHO International Clinical Trials Registry Platform, and ClinicalTrials.gov for RCTs and observational studies that evaluated treatment responses to pharmacological management in COVID-19 patients, from inception to June $9^{\text {th }}, 2020$. Reference lists of review articles were also reviewed to search for additional articles that may not have been retrieved by the 
medRxiv preprint doi: https://doi.org/10.1101/2020.06.15.20132407; this version posted June 19, 2020. The copyright holder for this preprint

prespecified searching strategy. We had no restriction on language, but all included studies were written in English.

We contacted principal investigators of unpublished studies identified in trial registries and regulatory submissions to obtain unpublished data. Inclusion of unpublished data in NMAs is not uncommon ${ }^{4-11}$ and reduces risk of selection and publication bias while increasing the density of study data. This is especially beneficial in the study of COVID-19 as all data were generated relatively recently, and the bulk of the relevant data are still in the unpublished stages. Pre-prints have been used in meta-analysis relatively frequently for the urgent topic of COVID-19 $9^{9-12}$, and American Gastroenterological Association (AGA) recently published a management guideline for the gastrointestinal manifestation of COVID-19 patients based on the result of meta-analysis incorporating pre-prints ${ }^{11}$. We contacted authors of included preprints from medRxiv and SSRN, and any change in the results was updated.

We included both RCTs and baseline-adjusted observational studies; the rationale is that inclusion of real-world data from non-randomized studies has the potential to improve precision of findings from RCTs if appropriately integrated ${ }^{13}$ and that the volume of information provided by these studies is necessary to assess adverse events of low to moderate incidence ${ }^{14-16}$. As observational studies are more vulnerable to bias, we included only the studies that adjusted for relevant confounding variables through methods such as propensity score matching (PSM), inverse probability treatment weighting (IPTW), or regression model adjustment. Studies providing evidence that the risk for such confounding was low by establishing baseline similarity between the groups also met inclusion criteria (Appendix p5).

Following studies were excluded: studies without a proper control group; studies of children or adolescents (<18 years); observational studies with significant differences in baseline characteristics between groups and did not perform adequate adjustments; studies investigating the effect of medication initiated prior to the diagnosis of COVID-19 (e.g. ACEi/ARB for hypertensive patients).

\section{Data extraction and quality assessment}

The study search and data extraction were independently conducted by 3 authors (MS Kim, MH An, and WJ Kim). Manuscript and supplementary materials of the included studies were reviewed for relevant information which was extracted according to a pre-specified protocol. Any discrepancy or ambiguity in this process was resolved by discussion. Authors of certain included studies were contacted in case of missing or unclear information. Non-randomized studies were qualitatively assessed using the Newcastle-Ottawa Scale (NOS) ${ }^{17}$, and RCTs were assessed with the Jadad scale ${ }^{18}$. All studies were assessed for risk of bias using the RoB 2 tool for randomized studies and ROBINS-I tool for nonrandomized studies ${ }^{19}$. The quality of evidence of collective outcomes were estimated using the Grading of Recommendations 
medRxiv preprint doi: https://doi.org/10.1101/2020.06.15.20132407; this version posted June 19, 2020. The copyright holder for this preprint

(which was not certified by peer review) is the author/funder, who has granted medRxiv a license to display the preprint in perpetuity.

It is made available under a CC-BY-NC-ND 4.0 International license .

Assessment, Development, and Evaluation (GRADE) framework ${ }^{20}$. A comparison-adjusted funnel plot with Egger's test was constructed to assess for publication bias ${ }^{21}$.

Control groups consisted of patients who received standard care or placebo. Patients who received hydroxychloroquine or corticosteroids were subdivided according to the dosage they received. For hydroxychloroquine, most studies reported 400mg hydroxychloroquine daily for maintenance, and this was considered the standard prescription; patients who received daily maintenance dosage of over $600 \mathrm{mg}$ hydroxychloroquine were classified into a separate high-dose hydroxychloroquine group. For corticosteroids, average daily dosage of $40 \mathrm{mg}$ methylprednisolone (or equivalent) was regarded as the standard dosage, while $1-2 \mathrm{mg} / \mathrm{kg} / \mathrm{day}$ methylprednisolone (or equivalent) was regard as high dose. 1mg methylprednisolone was considered equivalent to $0.1875 \mathrm{mg}$ dexamethasone and $5 \mathrm{mg}$ hydrocortisone.

A critically ill patient was defined as a patient who received invasive mechanical ventilation or needed intensive care in the ICU before or soon after beginning the treatment of interest, while moderate-severe patients were defined as patients hospitalized in a non-ICU setting at admission. The mortality rate of patients included in our mortality analyses were $11.7 \%$ for moderate-severe (non-ICU) patients and $38.6 \%$ for critically ill (ICU) patients on average.

\section{Data synthesis and statistical analysis}

We conducted a random-effects network meta-analysis within a frequentist framework using STATA (Stata Corp, College Station, TX, US, version 15.0) and R (version 3.6.0) software ${ }^{22}$. Direct and indirect (and mixed) comparison were accomplished through the self-programmed routines of STATA ${ }^{2123}$ and the netmeta package of $\mathrm{R}^{24}$, as done in our previous work ${ }^{25}$. The effect estimation was in odds ratios (OR) for dichotomous variables and mean difference (MD) for continuous variables, both with $95 \%$ confidential intervals (CI). When median (interquartile range) was presented for continuous variables of interest, it was converted to mean (standard deviation) by calculation ${ }^{26} 27$. A two-sided p-value of less than 0.05 was regarded as statistically significant.

Statistical heterogeneity was estimated using restricted maximum likelihood method ${ }^{28}$ and expressed with Higgins $\mathrm{I}^{2}$ statistics and the Cochran $\mathrm{Q}$ test $^{29}$. The net heat plot was constructed to visualize the inconsistency matrix and detect specific comparisons which introduced large inconsistencies ${ }^{30}$. The rank of effect estimation for each treatment was investigated using the surface under the cumulative rank curve (SUCRA) of P rank score of $\mathrm{R}^{31}$.

Prespecified subgroup and sensitivity analyses were performed to determine whether the results were affected by the patient severity, treatment protocol, and study design. The primary outcomes were separately analyzed for moderate to severe patients (non-ICU at admission) and critically ill patients (ICU) as these patients may respond differently to 
medRxiv preprint doi: https://doi.org/10.1101/2020.06.15.20132407; this version posted June 19, 2020. The copyright holder for this preprint (which was not certified by peer review) is the author/funder, who has granted medRxiv a license to display the preprint in perpetuity.

It is made available under a CC-BY-NC-ND 4.0 International license .

treatments. Sensitivity analyses were conducted by restricting the analyses to only RCTs, only published studies, excluding studies with high/serious risk of bias, and excluding studies in which initiation of treatment was over 14 days after symptom onset.

\section{Patient and public involvement}

Neither any patients nor the public were involved in the design, conduct, and reporting of the research. The study protocol is publicly available on PROSPERO (CRD42020186527) and medRxiv.

\section{Results}

The initial search identified 5970 articles. These studies were assessed for inclusion using the prespecified inclusion and exclusion criteria described in methods. Title and abstract of 3,626 articles were assessed, and 251 studies were found suitable for full-text review. After excluding 202 studies, 16 RCTs and 33 baseline-adjusted observations studies were finally included in our network meta-analysis (Figure 1). Total of 20212 confounder-adjusted COVID-19 patients were included. Background characteristics and reference list of included studies are presented in the supplementary appendix pp113-170. The risk of bias in included studies were generally low to moderate (Supplementary appendix pp 63-108).

For both pairwise meta-analysis and network meta-analysis, the primary outcomes presented no evidence of heterogeneity (Appendix pp 12-47). Inconsistency, which represents discordance of direct and indirect comparisons, was also evaluated for outcomes, but none were subject to global inconsistency. The network of eligible comparisons for clinically relevant outcomes are presented in Figure 2. Detailed information of studies included in the analysis for cardiac adverse events are presented in Table 1, and the certainty of evidence (GRADE) for each outcome is summarized in Table 2.

\section{Mortality in ICU and non- ICU settings}

Tocilizumab (Odds ratio (OR) $0.31,95 \%$ confidence interval (CI) 0.18 to 0.54 , low certainty) and anakinra (OR $0.30,95 \%$ CI 0.11 to 0.80 , very low certainty) significantly reduced the mortality in moderate-to-severe patients hospitalized in a non-ICU setting compared to the control group (Figure 3A). This effect could not be confirmed in a parallel sensitivity analysis with only RCTs (Figure 3B) as no RCTs were conducted for either agent. In critically ill patients hospitalized in the ICU, high dose IVIG (OR 0.13 , 95\% CI 0.04 to 0.42 , low certainty) and tocilizumab (OR $0.67,95 \%$ CI 0.50 to 0.91 , low certainty) were shown to lower morality while corticosteroid therapy was shown to increase mortality (OR $2.40,95 \%$ CI 1.02 to 5.61, moderate certainty) (Figure 3C).

\section{Progression to severe pneumonia or admission to ICU}


medRxiv preprint doi: https://doi.org/10.1101/2020.06.15.20132407; this version posted June 19, 2020. The copyright holder for this preprint (which was not certified by peer review) is the author/funder, who has granted medRxiv a license to display the preprint in perpetuity.

It is made available under a CC-BY-NC-ND 4.0 International license .

Tocilizumab (OR $0.32,95 \%$ CI 0.16 to 065 , low certainty), anakinra (OR $0.22,95 \%$ CI 0.09 to 0.54 , very low certainty), and remdesivir (OR $0.31,95 \%$ CI 0.18 to 0.55 , high certainty) showed effectiveness in preventing progression to severe courses (Figure 3E). Only remdesivir was shown to be effective in the analysis using only RCTs (OR 0.31, 95\% CI 0.18 to 0.55 ) (Figure 3F).

\section{Viral clearance rate (negative conversion rate)}

The use of convalescent plasma (OR 11.39, 95\% CI 3.91 to 33.18, low certainty), hydroxychloroquine (OR 6.08, 95\% CI 2.74 to 13.48 , moderate certainty), and meplazumab (OR $8.67,95 \%$ CI 1.53 to 49.22 , very low certainty) showed significantly higher viral clearance rate compared to standard supportive therapy (Figure 4A). However, this effect of hydroxychloroquine and meplazumab was not replicated in the analysis of only RCTs (Figure 4B). The result was similar when using the continuous variable of time to viral clearance (days) as the outcome measure (Figure 4C, D).

\section{Time to treatment initiation from symptom onset}

The effect of the timing of hydroxychloroquine treatment initiation after the symptom onset (Figure 4E) was assessed. Treatment initiated after 14 days (MD -2.02, 95\% CI -7.03 to 3.00) from symptom onset did not reduce the time to viral clearance compared to standard care.

\section{QTe prolongation}

Compared to hydroxychloroquine monotherapy, the prolongation of QTc interval after treatment initiation was statistically significantly longer in the hydroxychloroquine plus azithromycin group (MD 20.79ms, 95\% CI 12.60 to 28.98, low certainty) (Figure 5A). The proportion of patients experiencing QTc prolongation (defined by QTc interval $>500 \mathrm{~ms}$ or $\Delta$ QTc $>60 \mathrm{~ms}$ ) was also significantly higher in the hydroxychloroquine plus azithromycin group compared to the control group (OR $1.85,95 \%$ CI 1.05 to 3.26, very low certainty) but not in the hydroxychloroquine monotherapy group, azithromycin monotherapy group, or high-dose hydroxychloroquine group (Figure 5B).

\section{Fatal cardiac complications: Torsades de pointes, cardiac arrest, and severe ventricular arrhythmia}

The associations between fatal cardiac complications and hydroxychloroquine, azithromycin, or hydroxychloroquine plus azithromycin therapy were analyzed (Figure 5C). Overall, treatment with hydroxychloroquine plus azithromycin showed a significant association (OR $2.25,95 \%$ CI 1.27 to 3.99 , low certainty) while others did not. We further subdivided the included studies based on prevalence of coronary artery disease (CAD) and congestive heart 
medRxiv preprint doi: https://doi.org/10.1101/2020.06.15.20132407; this version posted June 19, 2020. The copyright holder for this preprint (which was not certified by peer review) is the author/funder, who has granted medRxiv a license to display the preprint in perpetuity.

It is made available under a CC-BY-NC-ND 4.0 International license .

disease (CHD) at baseline. In studies in which $>10 \%$ of the baseline population had $\mathrm{CAD} / \mathrm{CHD}$, the risk of fatal cardiac complication was statistically significantly higher in patients receiving hydroxychloroquine plus azithromycin. In studies in which $<10 \%$ of the baseline population had $\mathrm{CAD} / \mathrm{CHD}$, no notable difference in incidence of fatal heart complication was observed in any treatment group.

\section{Non-cardiac serious adverse events}

High dose ( $>600 \mathrm{mg} /$ day) hydroxychloroquine was associated with increased non-cardiac serious adverse events (Figure 5D). In contrast, there was a protective tendency with a decreased rate of adverse events with remdesivir compared to standard care (OR 0.71, 95\% CI 0.55 to 0.92 , high certainty).

\section{Subgroup and sensitivity analysis}

The results of our subgroup and sensitivity analysis are reported in the Appendix pp 48-62. The assessments of other specific complications such as nausea/vomiting, diarrhea, hypoalbuminemia, anemia, leukopenia, lymphopenia, elevated AST/ALT, elevated CK, and increase total bilirubin are also presented in Appendix pp 52-54.

\section{Discussion}

This is the first network meta-analysis (NMA) of pharmacological treatment for COVID-19. We comprehensively analyzed 31 active pharmacologic agents and their combinations in a large-scale analysis incorporating 20212 confounder-adjusted patients. Our study included unpublished data to integrate recent investigations and avoid selection and publication bias, as done in previous studies ${ }^{4-7}$. We did not limit our inclusions to RCTs and incorporated observational studies as we deemed that, in this analysis, the inclusion of real-world evidence from non-randomized studies has the potential to add validity to certain findings ${ }^{13}$, provide additional information regarding low-to-moderate incidence adverse events ${ }^{14-16}$, and improve the density of the network ${ }^{14}$. Many previous NMAs included observational studies with this rationale ${ }^{14-16} 3233$, but inclusion of observational studies to an NMA requires careful integration to avoid biases from these observational studies pervading the meta-analysis ${ }^{34}$; as such, we exclusively included cohort studies that adjusted for confounders through methods such as propensity score matching (PSM), inverse probability treatment weighting (IPTW), and regression model adjustment or established similarity in the baseline characteristics of the groups being compared so that such adjustments are not necessary or irrelevant.

\section{Statement of principal findings}

Our conclusions support the use of individualized treatment strategies based on clinical setting and severity. For moderate and severe patients hospitalized in non-ICU settings, 
medRxiv preprint doi: https://doi.org/10.1101/2020.06.15.20132407; this version posted June 19, 2020. The copyright holder for this preprint

(which was not certified by peer review) is the author/funder, who has granted medRxiv a license to display the preprint in perpetuity.

It is made available under a CC-BY-NC-ND 4.0 International license .

tocilizumab and anakinra were shown to reduce risk of progression to severe pneumonia or ICU admission. Both of these selective anti-inflammatory agents also showed survival benefit compared to standard care. Remdesivir was the only antiviral agent shown to prevent progression of disease to severe pneumonia or transfer to ICU, but it did not alter mortality rate for non-ICU patients. For ICU-based critically ill patients, high dose IVIG and tocilizumab may reduce mortality while corticosteroid was associated with increased mortality. Convalescent plasma and hydroxychloroquine, topics of much debate, were not shown to reduce mortality rate or prevent progression to severe disease in our analysis; however, they demonstrated benefit in promoting viral clearance.

\section{Implications for clinicians and policymakers}

Our analysis showed that hydroxychloroquine was significantly associated with reduced time to viral clearance (Figure 4C). Although this result was not supported by a single RCT on this subject $^{35}$, this RCT should be interpreted with caution due to the median 16 days of delay from symptom onset to the treatment; our analysis indicated that the effects of hydroxychloroquine may fade after 14 days of delay from symptom onset to treatment initiation (Figure 4E). It should be noted that hydroxychloroquine was not shown to reduce mortality rate or progression to severe courses. As the level of evidence (GRADE assessment) varies in certainty for these results, further prospective large randomized trials with early initiation of treatment may be warranted to establish firm conclusions.

The potential cardiotoxicity of hydroxychloroquine and azithromycin is a widely shared concern in treating COVID-19 with these medications. According to our quantitative synthesis, incidence of QT prolongation was significantly higher in the patients who received hydroxychloroquine plus azithromycin compared to those who received standard care (Figure 5B). In addition, this combination of hydroxychloroquine and azithromycin was also associated with increased rate of fatal cardiac complications such as torsades de pointes, cardiac arrest, and severe ventricular arrhythmia in the cardiac-impaired population with a pooled incidence of $12.2 \%$; in comparison, the pooled fatal cardiac complications rate in healthy populations with preserved cardiac function was about $0 \%$. Therefore, the use of hydroxychloroquine/azithromycin should be limited to patients with healthy cardiac function, and monotherapy should be preferred to combination therapy for patients with poor cardiac function (Figure 5C). It should also be noted that non-cardiac adverse events were significantly more frequent in high dose $(>600 \mathrm{mg} /$ day) hydroxychloroquine monotherapy compared to standard care (Figure 5D); nausea, vomiting, and diarrhea that required discontinuation of the treatment were more frequent with high dose hydroxychloroquine intake. Strict monitoring should be implemented in all patients receiving hydroxychloroquine with or without azithromycin to maintain a tolerable safety margin.

The results of our study also showed the efficacy of remdesivir in reducing the progression of COVID-19 to more severe pneumonia or admission to the ICU (Figure 3E-F). This result was supported by a high certainty of evidence (Table 2) and was replicated in the sensitivity analysis that included only RCTs. Interestingly, non-cardiac serious adverse events occurred 
medRxiv preprint doi: https://doi.org/10.1101/2020.06.15.20132407; this version posted June 19, 2020. The copyright holder for this preprint

(which was not certified by peer review) is the author/funder, who has granted medRxiv a license to display the preprint in perpetuity.

It is made available under a CC-BY-NC-ND 4.0 International license .

significantly less in patients who received remdesivir compared to the control group (Figure 5D). This may be explained by the preventive effect of remdesivir against progression to severe diseases as numerous clinical trials reported possible consequences of severe disease such as septic shock and acute kidney injury as non-cardiac serious adverse events.

Tocilizumab (monoclonal IL-6 receptor antibody), anakinra (IL-1 receptor antagonist), and IVIG were associated with significantly reduced mortality in COVID-19 patients (Figure 3AD). These three agents are known anti-inflammatory agents that have been conventionally used in hyperimmune or autoimmune conditions; tocilizumab and anakinra have been used for the management of severe rheumatoid arthritis ${ }^{36}$ and juvenile idiopathic arthritis ${ }^{38-40}$, and IVIG was used for management of Kawasaki's disease ${ }^{41} 42$, inflammatory muscle diseases $^{4344}$, and sepsis ${ }^{45}$. As there is accumulating evidence for an hyper-immune response characterized by the release of pro-inflammatory cytokines in severe and deceased Covid-19 patients ${ }^{46-50}$, suppression of the inflammatory response and potential cytokine storm with immune-modulatory therapies was proposed as a potential therapeutic target; the results of this network meta-analysis support the efficacy of these treatments. Effectiveness of antiinflammatory agents (tocilizumab, anakinra, IVIG) and ineffectiveness of antiviral agents, except for remdesivir, in hospitalized COVID-19 patients suggest that the management should focus more on the immune response rather than viral mechanism itself. Although numerous studies reported consistent results on beneficial effect of such agents, the certainty of evidence for these agents are either low or very low because conclusions on tocilizumab, anakinra, and IVIG to date are all based on observational studies. Randomized controlled trials on these anti-inflammatory agents are required to confirm these findings and increase the level of evidence.

Corticosteroids, on the other hand, were associated with significantly increased risk of morality in critically ill COVID-19 patients (Figure 3C). It could be argued that the frequent use of corticosteroids on patients with more severe conditions may have skewed the results against corticosteroid use; however, the studies included in our synthesis have adjusted for confounders for mortality including severity of disease, implicating that the observed unsafe effect of corticosteroids in critically ill COVID-19 should not be neglected. The detrimental effects of corticosteroid on mortality is in line with previous studies that showed the higher mortality rate with adjuvant steroid use in HIN1 influenza-infected critically ill patients in the ICU due to increased rates of superinfection and non-selective suppression of immune responses $^{51-53}$.

\section{Limitations}

Our study has several limitations. First, some of the results were derived from a single study (i.e., Anakinra) or studies with high risk of bias. To account for such weakness in evidence, we assessed the certainty of evidence for each outcome using the GRADE framework as summarized in Table 2. Second, for certain treatment agents, many articles have been 
medRxiv preprint doi: https://doi.org/10.1101/2020.06.15.20132407; this version posted June 19, 2020. The copyright holder for this preprint (which was not certified by peer review) is the author/funder, who has granted medRxiv a license to display the preprint in perpetuity.

It is made available under a CC-BY-NC-ND 4.0 International license .

published among which only one or few have been included in our analysis (e.g. convalescent plasma). This is because we prospectively collected studies adhere to predefined inclusion criteria, and studies that did not adequately account for confounding or those prone to significant bias were filtered out. The excluded studies are listed and described in the supplementary appendix pp 171-174 with reasons for exclusion. Third, we included observational studies and unpublished data. While such inclusions may introduce biases into the final analysis, we judged the benefits overweigh the risks for reasons we mentioned in methods. Furthermore, we attempted to minimize biases by exclusively including observational studies with confounder-adjustment and further conducted sensitivity analyses in which the same analysis was performed using only RCTs or only published studies (Appendix pp 55-58). Lastly, some of the results derived from this NMA lacks the support of pairwise meta-analysis. However, the methodological power of NMA is credible as empirical evidence supported that NMAs were $20 \%$ more likely to provide stronger evidence against the null hypothesis than conventional pairwise meta-analyses ${ }^{54}$. Accordingly, our NMA can offer meaningful implications for guiding management of COVID-19 until future studies build up stronger evidence.

\section{Conclusion}

Anti-inflammatory agents (tocilizumab, anakinra, and IVIG) and remdesivir may safely and effectively improve clinical outcomes of COVID-19. Widely used hydroxychloroquine provides marginal clinical benefit in improving viral clearance rates whilst posing both cardiac and non-cardiac safety risks. Only $20 \%$ of current evidence on pharmacological management of COVID-19 is on moderate/high evidence certainty and can be considered in practice and policy; remaining $80 \%$ are of low or very low certainty and warrant further studies to establish firm conclusions.

\section{Funding}

There was no funding source for this study. MS Kim and MH An had full access to all of the data in the study and MS Kim and T Hwang had final decision responsibility to submit for publication.

\section{Contributors}

MS Kim and MH An contributed to the study concept and design. MS Kim, MH An, and WJ Kim identified and acquired relevant trials and extracted data. MS Kim and WJ Kim drafted the protocol for this study. MS Kim and MH An analyzed and interpreted the data. MS Kim and MH An wrote the first draft of the manuscript. T Hwang contributed to the interpretation of data and critical revision of the manuscript. All authors saw and approved the final 
submitted version.

\section{Competing interests}

All authors have completed the ICMJE uniform disclosure form at www.icmje.org/coi_disclosure.pdf (available on request from the corresponding author) and declare: no support from any organization for the submitted work; no financial relationships with any organizations that might have an interest in the submitted work in the previous three years; no other relationships or activities that could appear to have influenced the submitted work.

\section{Ethical approval}

Not required

\section{Data sharing}

Not applicable

\section{Dissemination declare:}

Not applicable

\section{Transparency}

The manuscript's guarantor (MSK) affirms that this manuscript is an honest, accurate, and transparent account of study being reported; that no important aspects of the study have been omitted; and that any discrepancies from the study as planned have been explained.

\section{References}

1. Mehra MR, Ruschitzka F, Patel AN. Retraction;Hydroxychloroquine or chloroquine with or without a macrolide for treatment of COVID-19: a multinational registry analysis. Lancet 2020; doi: 10.1016/S0140-6736(20)31324-6

2. Ma Z, Liu J, Pan Q. Overwhelming COVID-19 Clinical Trials: Call for Prospective Metaanalysis. Trends Pharmacol Sci 2020; 20:S0165-6147(20)30126-7.

3. Higgins JP, Welton NJ. Network meta-analysis: a norm for comparative effectiveness? The Lancet 2015;386(9994):628-30.

4. Huhn M, Nikolakopoulou A, Schneider-Thoma J, et al. Comparative efficacy and tolerability of 32 oral antipsychotics for the acute treatment of adults with multi-episode schizophrenia: a systematic review and network meta-analysis. Lancet 2019;394(10202):939- 
medRxiv preprint doi: https://doi.org/10.1101/2020.06.15.20132407; this version posted June 19, 2020. The copyright holder for this preprint (which was not certified by peer review) is the author/funder, who has granted medRxiv a license to display the preprint in perpetuity.

51.

5. Slee A, Nazareth I, Bondaronek P, et al. Pharmacological treatments for generalised anxiety disorder: a systematic review and network meta-analysis. Lancet 2019; 393(10173):768-777. doi: 10.1016/S0140-6736(18)31793-8.

6. Eyding D, Lelgemann M, Grouven U, et al. Reboxetine for acute treatment of major depression: systematic review and meta-analysis of published and unpublished placebo and selective serotonin reuptake inhibitor controlled trials. BMJ 2010;341:c4737.

7. Jinatongthai P, Kongwatcharapong J, Foo CY, et al. Comparative efficacy and safety of reperfusion therapy with fibrinolytic agents in patients with ST-segment elevation myocardial infarction: a systematic review and network meta-analysis. Lancet 2017;390(10096):747-59.

8. Langhorne P, Ramachandra S, Collaboration SUT. Organised inpatient (stroke unit) care for stroke: network meta $\square$ analysis. Cochrane Database Syst Rev 2020;4(4):CD000197.

9. Wynants L, Van Calster B, Bonten MM, et al. Prediction models for diagnosis and prognosis of covid-19 infection: systematic review and critical appraisal. BMJ 2020; 369:m1328.

10. Li J-W, Han T-W, Woodward M, et al. The impact of 2019 novel coronavirus on heart injury: A systemic review and Meta-analysis. Prog Cardiovasc Dis 2020;S00330620(20)30080-3.

11. Sultan S, Altayar O, Siddique SM, et al. AGA Institute Rapid Review of the GI and Liver Manifestations of COVID-19, Meta-Analysis of International Data, and Recommendations for the Consultative Management of Patients with COVID-19. Gastroenterology 2020; S0016-5085(20)30593-X.

12. Viner RM, Russell SJ, Croker H, et al. School closure and management practices during coronavirus outbreaks including COVID-19: a rapid systematic review. Lancet Child Adolesc Health 2020;4(5):397-404. doi: 10.1016/S2352-4642(20)30095-X.

13. Efthimiou O, Mavridis D, Debray TP, et al. Combining randomized and non $\square$ randomized evidence in network meta $\square$ analysis. Stat Med 2017;36(8):1210-26.

14. Marconi E, Bettiol A, Ambrosio G, et al. Efficacy and safety of pharmacological treatments for Patent Ductus Arteriosus closure: a systematic review and network metaanalysis of clinical trials and observational studies. Pharmacol Res 2019:104418.

15. Tricco AC, Zarin W, Cardoso R, et al. Efficacy, effectiveness, and safety of herpes zoster vaccines in adults aged 50 and older: systematic review and network meta-analysis. BMJ 2018;363:k4029.

16. Zeng C, Wei J, Persson MS, et al. Relative efficacy and safety of topical non-steroidal anti-inflammatory drugs for osteoarthritis: a systematic review and network meta-analysis of randomised controlled trials and observational studies. Br J Sports Med 2018;52(10):642-50.

17. Wells G, Shea B, O'connell D, et al. The Newcastle-Ottawa Scale (NOS) for assessing the quality of nonrandomised studies in meta-analyses. Ottawa (ON): Ottawa Hospital Research Institute; 2009. Available in March 2016

18. Clark HD, Wells GA, Huët C, et al. Assessing the quality of randomized trials: reliability of the Jadad scale. Control Clin Trials 1999;20(5):448-52.

19. Sterne JA, Hernán MA, Reeves BC, et al. ROBINS-I: a tool for assessing risk of bias in non-randomised studies of interventions. BMJ 2016;355:i4919.

20. Puhan MA, Schünemann HJ, Murad MH, et al. A GRADE Working Group approach for rating the quality of treatment effect estimates from network meta-analysis. $B M J$ 2014;349:g5630.

21. Chaimani A, Higgins JP, Mavridis D, et al. Graphical tools for network meta-analysis in STATA. Plos One 2013;8(10):e76654. 
medRxiv preprint doi: https://doi.org/10.1101/2020.06.15.20132407; this version posted June 19, 2020. The copyright holder for this preprint (which was not certified by peer review) is the author/funder, who has granted medRxiv a license to display the preprint in perpetuity. It is made available under a CC-BY-NC-ND 4.0 International license .

22. Xu C, Niu Y, Wu J, et al. Software and package applicating for network meta $\square$ analysis: A usage $\square$ based comparative study. J Evid Based Med 2018;11(3):176-83.

23. Shim S, Yoon B-H, Shin I-S, et al. Network meta-analysis: application and practice using Stata. Epidemiol Health 2017;39:e2017047.

24. Neupane B, Richer D, Bonner AJ, et al. Network meta-analysis using R: a review of currently available automated packages. Plos One 2014;9(12):e115065.

25. Kim MS, Rhim HC, Park A, et al. Comparative efficacy and acceptability of pharmacological interventions for the treatment and prevention of delirium: A systematic review and network meta-analysis. $J$ Psychiatr Res 2020;125:164-176. doi: 10.1016/j.jpsychires.2020.03.012.

26. Hozo SP, Djulbegovic B, Hozo I. Estimating the mean and variance from the median, range, and the size of a sample. BMC Med Res Methodol 2005;5(1):13.

27. Wan X, Wang W, Liu J, et al. Estimating the sample mean and standard deviation from the sample size, median, range and/or interquartile range. BMC Med Res Methodol 2014;14(1):135.

28. Lumley T. Network meta $\square$ analysis for indirect treatment comparisons. Stat Med 2002;21(16):2313-24.

29. Higgins J, Thompson SG. Quantifying heterogeneity in a meta $\square$ analysis. Stat Med 2002;21(11):1539-58.

30. Krahn U, Binder H, König J. A graphical tool for locating inconsistency in network metaanalyses. BMC Med Res Methodol 2013;13(1):35.

31. Rücker G, Schwarzer G. Ranking treatments in frequentist network meta-analysis works without resampling methods. BMC Med Res Methodol 2015;15(1):58.

32. Kanters S, Socias ME, Paton NI, et al. Comparative efficacy and safety of second-line antiretroviral therapy for treatment of HIV/AIDS: a systematic review and network metaanalysis. Lancet HIV 2017;4(10):e433-e41.

33. Datta S, Shah L, Gilman RH, et al. Comparison of sputum collection methods for tuberculosis diagnosis: a systematic review and pairwise and network meta-analysis. Lancet Glob Health 2017;5(8):e760-e71.

34. Cameron C, Fireman B, Hutton B, et al. Network meta-analysis incorporating randomized controlled trials and non-randomized comparative cohort studies for assessing the safety and effectiveness of medical treatments: challenges and opportunities. Syst Rev 2015;4(1):147.

35. Tang W, Cao Z, Han M, et al. Hydroxychloroquine in patients with mainly mild to moderate coronavirus disease 2019: open label, randomised controlled trial. $B M J$ 2020;369:m1849. doi: 10.1136/bmj.m1849

36. Singh JA, Beg S, Lopez-Olivo MA. Tocilizumab for rheumatoid arthritis: a Cochrane systematic review. J Rheumatol 2011;38(1):10-20.

37. Smolen JS, Beaulieu A, Rubbert-Roth A, et al. Effect of interleukin-6 receptor inhibition with tocilizumab in patients with rheumatoid arthritis (OPTION study): a double-blind, placebo-controlled, randomised trial. Lancet 2008;371(9617):987-97.

38. Sahraoui A, Kloster-Jensen K, Ueland T, et al. Anakinra and tocilizumab enhance survival and function of human islets during culture: implications for clinical islet transplantation. Cell transplant 2014;23(10):1199-211. doi: 10.3727/096368913x667529 [published Online First: 2013/05/03]

39. Nigrovic PA, Mannion M, Prince FH, et al. Anakinra as first $\square$ line disease $\square$ modifying therapy in systemic juvenile idiopathic arthritis: report of forty $\square$ six patients from an international multicenter series. Arthritis Rheum 2011;63(2):545-55.

40. Yokota S, Imagawa T, Mori M, et al. Efficacy and safety of tocilizumab in patients with 
medRxiv preprint doi: https://doi.org/10.1101/2020.06.15.20132407; this version posted June 19, 2020. The copyright holder for this preprint (which was not certified by peer review) is the author/funder, who has granted medRxiv a license to display the preprint in perpetuity. It is made available under a CC-BY-NC-ND 4.0 International license .

systemic-onset juvenile idiopathic arthritis: a randomised, double-blind, placebo-controlled, withdrawal phase III trial. Lancet 2008;371(9617):998-1006.

41. Toubiana J, Poirault C, Corsia A, et al. Kawasaki-like multisystem inflammatory syndrome in children during the covid-19 pandemic in Paris, France: prospective observational study. BMJ 2020;369

42. Oates $\square$ Whitehead RM, Baumer JH, Haines L, et al. Intravenous immunoglobulin for the treatment of Kawasaki disease in children. Cochrane Database Syst Rev 2003;2003(4):CD004000.

43. Hughes RA, Swan AV, van Doorn PA. Cochrane Review: Intravenous immunoglobulin for Guillain $\square$ Barré syndrome. Cochrane Database Syst Rev 2012 Jul 11;(7):CD002063.

44. Nimmerjahn F, Ravetch JV. Anti-inflammatory actions of intravenous immunoglobulin. Annu Rev Immunol 2008;26:513-33.

45. Alejandria MM, Lansang MAD, Dans LF, et al. Intravenous immunoglobulin for treating sepsis, severe sepsis and septic shock. Cochrane Database Syst Rev 2013;2013(9):CD001090. 46. Khan F, Fabbri L, Stewart I, et al. A systematic review of Anakinra, Tocilizumab, Sarilumab and Siltuximab for coronavirus-related infections. medRxiv [preprint] 2020:2020.04.23.20076612. doi: 10.1101/2020.04.23.20076612

47. Qin C, Zhou L, Hu Z, et al. Dysregulation of immune response in patients with COVID19 in Wuhan, China. Clin Infect Dis 2020 doi: 10.1093/cid/ciaa248 [published Online First: 2020/03/13]

48. Chen $\mathrm{T}, \mathrm{Wu} \mathrm{D}$, Chen $\mathrm{H}$, et al. Clinical characteristics of 113 deceased patients with coronavirus disease 2019: retrospective study. BMJ 2020;368

49. Mehta P, McAuley DF, Brown M, et al. COVID-19: consider cytokine storm syndromes and immunosuppression. Lancet 2020;395(10229):1033.

50. Cao X. COVID-19: immunopathology and its implications for therapy. Nat Rev Immunol 2020;20(5):269-70.

51. Kim SH, Hong SB, Yun SC, et al. Corticosteroid treatment in critically ill patients with pandemic influenza A/H1N1 2009 infection: analytic strategy using propensity scores. Am J Respir Crit Care Med 2011;183(9):1207-14. doi: 10.1164/rccm.201101-0110OC.

52. Liem NT, Tung CV, Hien ND, et al. Clinical features of human influenza A (H5N1) infection in Vietnam: 2004-2006. Clin Infect Dis 2009;48(12):1639-46.

53. Abdel-Ghafar A, Chotpitayasunondh T, Gao Z, et al. Writing committee of the second world health organization consultation on clinical aspects of human infection with avian influenza A (H5N1) virus. Update on avian influenza A (H5N1) virus infection in humans. $N$ Engl J Med 2008;358(3):261-73.

54. Nikolakopoulou A, Mavridis D, Furukawa TA, et al. Living network meta-analysis compared with pairwise meta-analysis in comparative effectiveness research: empirical study. BMJ 2018;360:k585. doi: 10.1136/bmj.k585. 
medRxiv preprint doi: https://doi.org/10.1101/2020.06.15.20132407; this version posted June 19, 2020. The copyright holder for this preprint (which was not certified by peer review) is the author/funder, who has granted medRxiv a license to display the preprint in perpetuity.

It is made available under a CC-BY-NC-ND 4.0 International license .

\section{Figure legends}

Figure 1. PRISMA diagram showing selection of articles for pairwise and network metaanalysis

Figure 2: Network of eligible comparisons for primary outcomes

(A) Mortality for moderate-severe COVID-19 patients (non-ICU at admission). (B) mortality for critically ill patients (ICU). (C) Progression of disease to severe courses (i.e. progression to severe pneumonia and/or admission to ICU). (D) Time to viral clearance (days). (E) Fatal cardiac adverse events (torsades de pointes, cardiac arrest, and severe ventricular arrhythmia). (F) Non-cardiac serious adverse events. Lines indicate direct comparison of agents, and the thickness of line corresponds to the number of trials in the comparison. Size of node corresponds to the number of studies that involve the intervention. HQ = Hydroxychloroquine. Lop/R = Lopinavir-Ritonavir. ICU = intensive care unit.

Figure 3: Network meta-analysis of pharmacological interventions compared with control (standard care) for efficacy outcomes.

Mortality for moderate-severe patients (non-ICU at admission) from (A) all studies and (B) RCTs only. Mortality for critically ill patients (ICU) from (C) all studies and (D) RCTs only. Progression to severe course (i.e. progression to severe pneumonia and/or admission to ICU) from (E) all studies and (F) RCTs only. Effect estimates are presented in odds ratios (OR) with 95\% CI. Pharmacological agents are ranked by surface under the cumulative ranking curve $($ SUCRA) value. RCT $=$ randomized controlled trial. $\mathrm{ICU}=$ intensive care unit.

Figure 4: Network meta-analysis of pharmacological interventions compared with control (standard care) for viral clearance.

Viral clearance rate (proportion of patients converted to PCR-negative status) from (A) all studies and (B) RCTs only. Time to viral clearance (days) from (C) all studies and (D) RCTs only. (E) Time to viral clearance from different hydroxychloroquine treatment initiation timings after symptom onset. Effect estimates are presented in odds ratios (OR) for viral clearance rate and mean differences (MD) for time to viral clearance, with 95\% CI. Pharmacological agents are ranked by surface under the cumulative ranking curve (SUCRA) value. $\mathrm{RCT}=$ randomized controlled trial.

Figure 5: Network meta-analysis of safety of different pharmacological interventions.

(A) Change in QTc interval $(\triangle \mathrm{QTc})$ from baseline (msec). (B) Proportion of patients experiencing QTc prolongation ( $>500 \mathrm{~ms}$ or $\Delta \mathrm{QTc}>60 \mathrm{~ms}$ ). (C) Fatal cardiac complication after hydroxychloroquine administration (torsades de pointes, cardiac arrest, and severe ventricular arrhythmia). (D) Non-cardiac serious adverse events. Effect estimates are presented in odds ratios (OR) and mean differences (MD) with 95\% CI. Pharmacological agents are ranked by surface under the cumulative ranking curve (SUCRA) value. CAD = coronary artery disease. $\mathrm{CHD}=$ congestive heart disease. $\mathrm{HQ}=$ hydroxychloroquine. 
Table 1. Studies included for analysis of QT prolongation and fatal cardiac complications after taking hydroxychloroquine alone or hydroxychloroquine with azithromycin.

\begin{tabular}{|c|c|c|c|}
\hline Study & Baseline characteristics & $\begin{array}{l}\text { Assessed fatal cardiac } \\
\text { complications }\end{array}$ & Incidence $(\%)$ \\
\hline \multicolumn{4}{|c|}{ Studies including relatively high portion of patients with poor cardiac function $(>10 \%$ of patients have CAD/CHD*) } \\
\hline Rosenberg et al. & $\begin{array}{l}\text { Proportion of patients with cardiovascular comorbidities was high at } \\
\text { baseline (approximately } 30 \% \text { ), and proportions of cardiovascular } \\
\text { comorbidities were significantly different between groups in crude } \\
\text { analysis. However, adjustments were made for sex, age category ( }<65 \\
\text { vs } \geq 65 \text { years), diabetes, any chronic lung disease, cardiovascular disease, } \\
\text { abnormal chest imaging, respiration rate }>22 / \text { min, O } 2 \text { saturation }<90 \% \text {, } \\
\text { elevated creatinine, and AST }>40 \text { U/L. Adjusted odds ratios for prolonged } \\
\text { QT interval were presented. } \\
\text { Obesity was significantly higher in pharmacologic treatment groups } \\
\text { (hydroxychloroquine, hydroxychloroquine, alone, and azithromycin } \\
\text { alone) compared to control (neither drug). Obesity was not adjusted for. } \\
\text { - Median age } 63 \\
\text { - Coronary heart disease }(12.7 \%)\end{array}$ & Cardiac arrest & $\begin{array}{l}\text { Hydroxychloroquine+Azithromycin: } 15.5 \% \\
\text { Hydroxychloroquine alone: } 13.6 \% \\
\text { Azithromycin alone: } 6.1 \% \\
\text { Neither drugs: } 7.1 \%\end{array}$ \\
\hline Mercuro et al. & $\begin{array}{l}\text { Baseline QTc interval was longer in the hydroxychloroquine group } \\
\text { compared to hydroxychloroquine plus azithromycin group. Therefore, we } \\
\text { used the change in QTc intervals ( } \Delta \text { QTc) in each group for analysis. } \\
\text { - Mean age } 60.1 \\
\text { - Coronary heart disease }(11.1 \%) \text { and atrial fibrillation }(13.3 \%)\end{array}$ & Torsades de pointes & $\begin{array}{l}\text { Hydroxychloroquine+Azithromycin: } 1.8 \% \\
\text { Hydroxychloroquine: } 0 \%\end{array}$ \\
\hline Ramireddy et al. & $\begin{array}{l}\text { Baseline QTc intervals were significantly different between groups. } \\
\text { Therefore, we used change in QTc intervals (posttreatment QTc-baseline } \\
\text { QTc, } \Delta \text { QTc) of each group for analysis. } \\
\text { - Mean age } 62.3 \text {, mean BMI } 27.8 \\
\text { - Heart failure }(20 \%)\end{array}$ & $\begin{array}{l}\text { Syncope, torades de } \\
\text { pointes, or other } \\
\text { lethal arrhythmias }\end{array}$ & $\begin{array}{l}\text { Azithromycin alone: } 0 \% \\
\text { Hydroxychloroquine+Azithromycin: } 0 \%\end{array}$ \\
\hline Saleh et al. & $\begin{array}{l}\text { Sex, structural heart disease, cirrhosis, other medications known to cause } \\
\text { QT prolongation were comparable between hydroxychloroquine and } \\
\text { hydroxychloroquine plus azithromycin groups. }\end{array}$ & $\begin{array}{l}\text { Monomorphic } \\
\text { ventricular } \\
\text { arrhythmia }\end{array}$ & $\begin{array}{l}\text { Hydroxychloroquine: } 2.4 \% \\
\text { Hydroxychloroquine+Azithromycin: } 5.0 \%\end{array}$ \\
\hline
\end{tabular}




\begin{tabular}{|c|c|c|c|}
\hline & $\begin{array}{l}\text { - Mean age 58.5, mean BMI } 28.2 \\
\text { - Mean ejection fraction }(61.9 \%) \text {, coronary artery disease }(11.4 \%)\end{array}$ & & \\
\hline Bessiere et al. & $\begin{array}{l}\text { ICU setting. } \\
\text {-Median age 68, median BMI } 28 \\
\text {-Structural heart disease (20\%) }\end{array}$ & $\begin{array}{l}\text { Severe ventricular } \\
\text { arrhythmia including } \\
\text { torades de pointes }\end{array}$ & $\begin{array}{l}\text { Hydroxychloroquine: } 0 \% \\
\text { Hydroxychloroquine+Azithromycin: } 0 \%\end{array}$ \\
\hline Borba et al. & $\begin{array}{l}\text { Randomized controlled trial. } \\
\text { Generally, baseline characteristics were well controlled between groups, } \\
\text { but pre-existing heart disease was more frequent in the high dosage group } \\
\text { (p value not provided). } \\
\text { - Mean age } 51.1 \\
\text { - Heart disease }(17.9 \%) \text { in high dose hydroxychloroquine group }\end{array}$ & $\begin{array}{l}\text { Ventricular } \\
\text { tachycardia }\end{array}$ & $\begin{array}{l}\text { High dose hydroxychloroquine: } 4.8 \% \\
\text { Standard dose hydroxychloroquine: } 0 \%\end{array}$ \\
\hline \multicolumn{4}{|c|}{ Studies including relatively low portion of patients with poor cardiac function $(<10 \%$ of patients have CAD/CHD*) } \\
\hline Mahevas et al. & $\begin{array}{l}\text { Baseline characteristics were generally balanced and controlled (i.e., } \\
\text { COPD/asthma, HF, CVD, DM, CKD, LC, immunosuppression). } \\
\text { - Median age } 60 \\
\text { - Chronic heart failure }(4 \%)\end{array}$ & Severe arrhythmia & $\begin{array}{l}\text { Hydroxychloroquine: } 1.1 \% \text { (first-degree } \\
\text { atrioventricular block) } \\
\text { no hydroxychloroquine: } 1.0 \% \text { (left bundle } \\
\text { branch block) }\end{array}$ \\
\hline Tang et al. & $\begin{array}{l}\text { Randomized controlled trial. } \\
\text { Mild to moderate patients with low rate of cardiovascular comorbidity } \\
\text { presence. } \\
\text { - Mean age } 46.1 \text {, BMI } 23.5 \\
\text { - Hypertension was presented in } 6 \% \text { of patients, and the prevalence of } \\
\text { structural heart disease is expected to be less than } 6 \%\end{array}$ & Severe arrhythmia & $\begin{array}{l}\text { High dose hydroxychloroquine: } 0 \% \\
\text { No hydroxychloroquine: } 0 \%\end{array}$ \\
\hline Kim et al. & $\begin{array}{l}\text { Patients in the conservative treatment group had milder baseline features } \\
\text { than patients in the hydroxychloroquine plus azithromycin group. } \\
\text { - Mean age } 42.2 \text { and mean BMI } 23 \\
\text { - Very low prevalence of cardiovascular comorbidities, perhaps due to } \\
\text { young age. }\end{array}$ & Cardiac arrest & $\begin{array}{l}\text { Hydroxychloroquine+Azithromycin: } 0 \% \\
\text { No hydroxychloroquine: } 0 \%\end{array}$ \\
\hline Boulware et al. & $\begin{array}{l}\text { Randomized controlled trial. } \\
\text { Mild patient group. }\end{array}$ & Cardiac arrhythmia & $\begin{array}{l}\text { High dose hydroxychloroquine: } 0 \% \\
\text { No hydroxychloroquine: } 0 \%\end{array}$ \\
\hline
\end{tabular}


Only the adverse event-related data from this study was used in this

network meta-analysis, as this study investigates the effect of

hydroxychloroquine as a prophylactic measure which is not the focus of

our meta-analysis.

- Median age 41

- Cardiovascular disease $(0.7 \%$, not include hypertension)

$\mathrm{CAD} / \mathrm{CHD}$ : coronary artery disease / congestive heart disease.

COPD: chronic obstructive pulmonary disease. HF: heart failure. CVD: cardiovascular disease. DM: diabetes mellitus. LC: liver cirrhosis 
Table 2. Certainty of evidence evaluated with Grading of Recommendations Assessment, Development, and Evaluation (GRADE) framework

\begin{tabular}{|c|c|c|c|c|c|c|c|c|}
\hline Comparisons (vs. Control) & Effect size $(95 \% \mathrm{CI})$ & $\begin{array}{l}\text { Study design } \\
\text { (starting point) }\end{array}$ & Risk of bias & Inconsistency & Indirectness & Imprecision & Publication bias & GRADE \\
\hline \multicolumn{9}{|c|}{ Mortality in moderate to severe patients (non-ICU at admission) } \\
\hline Ruxolitinib & OR $0.13(0.01,2.72)$ & RCT (high) & No downgrade & Downgrade* & No downgrade & Downgrade & No downgrade & Low \\
\hline Interferon-b1a & OR $0.13(0.01,2.94)$ & RCT (high) & No downgrade & Downgrade* & No downgrade & Downgrade & No downgrade & Low \\
\hline Tocilizumab & OR $0.31(0.18,0.54)$ & Observational study (low) & No downgrade & No downgrade & No downgrade & No downgrade & No downgrade & Low \\
\hline Anakinra & OR $0.30(0.11,0.80)$ & Observational study (low) & No downgrade & Downgrade* & No downgrade & No downgrade & No downgrade & Very low \\
\hline Convalescent plasma & OR $0.17(0.01,3.93)$ & RCT (high) & No downgrade & Downgrade* & No downgrade & Downgrade & No downgrade & Low \\
\hline High dose corticosteroid & OR $0.44(0.17,1.14)$ & Observational study (low) & No downgrade & No downgrade & No downgrade & No downgrade & No downgrade & Low \\
\hline Azithromycin & OR $0.50(0.24,1.06)$ & Observational study (low) & No downgrade & Downgrade* & No downgrade & No downgrade & No downgrade & Very low \\
\hline $\begin{array}{l}\text { Hydroxychloroquine plus } \\
\text { azithromycin plus zinc }\end{array}$ & OR $0.56(0.28,1.06)$ & Observational study (low) & No downgrade & Downgrade* & Downgrade & No downgrade & No downgrade & Very low \\
\hline High dose IVIG & OR $0.48(0.02,9.79)$ & Observational study (low) & No downgrade & Downgrade* & No downgrade & Downgrade & No downgrade & Low $\ddagger$ \\
\hline Remdesivir & OR $0.65(0.38,1.11)$ & RCT (high) & No downgrade & No downgrade & No downgrade & No downgrade & No downgrade & High \\
\hline $\begin{array}{l}\text { Lopinavir-Ritonavir plus } \\
\text { arbidol }\end{array}$ & OR $0.62(0.03,11.65)$ & Observational study (low) & Downgrade & Downgrade* & Downgrade & Downgrade & No downgrade & Very low \\
\hline Lopinavir-Ritonavir & OR $0.71(0.33,1.53)$ & RCT (high) & No downgrade & Downgrade* & No downgrade & No downgrade & No downgrade & Moderate \\
\hline Hydroxychloroquine & OR $0.92(0.73,1.16)$ & Observational study (low) & No downgrade & No downgrade & No downgrade & No downgrade & No downgrade & Low \\
\hline $\begin{array}{l}\text { Hydroxychloroquine plus } \\
\text { azithromycin }\end{array}$ & OR $1.13(0.85,1.52)$ & Observational study (low) & No downgrade & No downgrade & No downgrade & No downgrade & No downgrade & Low \\
\hline IVIG & OR $1.76(0.33,9.32)$ & Observational study (low) & No downgrade & Downgrade* & No downgrade & Downgrade & No downgrade & Low $\ddagger$ \\
\hline Corticosteroid & OR $1.55(0.75,3.19)$ & Observational study (low) & No downgrade & Downgrade* & No downgrade & No downgrade & No downgrade & Low $\ddagger$ \\
\hline \multicolumn{9}{|c|}{ Mortality in critically ill patients (ICU) } \\
\hline High dose IVIG & OR $0.13(0.04,0.42)$ & Observational study (low) & No downgrade & Downgrade* & No downgrade & No downgrade & No downgrade & Low $\ddagger$ \\
\hline a-Lipoic acid & OR $0.17(0.02,1.46)$ & RCT (high) & No downgrade & Downgrade* & No downgrade & Downgrade & No downgrade & Low \\
\hline Interferon-b1a & OR $0.47(0.13,1.65)$ & RCT (high) & No downgrade & Downgrade* & No downgrade & Downgrade & No downgrade & Low \\
\hline Tocilizumab & OR $0.67(0.59,0.91)$ & Observational study (low) & No downgrade & No downgrade & No downgrade & No downgrade & No downgrade & Low \\
\hline Convalescent plasma & OR $0.72(0.23,2.29)$ & RCT (high) & No downgrade & Downgrade* & No downgrade & Downgrade & No downgrade & Low \\
\hline IVIG & OR $0.73(0.26,2.02)$ & Observational study (low) & No downgrade & Downgrade* & No downgrade & Downgrade & No downgrade & Low $\ddagger$ \\
\hline Remdesivir & OR $0.92(0.50,1.69)$ & RCT (high) & No downgrade & Downgrade* & No downgrade & No downgrade & No downgrade & Moderate \\
\hline Corticosteroid & OR $2.40(1.02,5.61)$ & Observational study (low) & No downgrade & No downgrade & No downgrade & Downgrade & No downgrade & Low $\ddagger$ \\
\hline \multicolumn{9}{|c|}{ Progression to severe course (progress to severe pneumonia or admission to ICU) } \\
\hline Ruxolitinib & OR $0.09(0.00,1.89)$ & RCT (high) & No downgrade & Downgrade* & No downgrade & Downgrade & No downgrade & Low \\
\hline Anakinra & OR $0.22(0.09,0.54)$ & Observational study (low) & No downgrade & Downgrade* & No downgrade & No downgrade & No downgrade & Very low \\
\hline Remdesivir & OR $0.31(0.18,0.55)$ & RCT (high) & No downgrade & No downgrade & No downgrade & No downgrade & No downgrade & High \\
\hline Tocilizumab & OR $0.32(0.16,0.65)$ & Observational study (low) & No downgrade & No downgrade & No downgrade & No downgrade & No downgrade & Low \\
\hline Arbidol plus interferon-a & OR $0.23(0.01,5.29)$ & Observational study (low) & No downgrade & Downgrade* & No downgrade & Downgrade & No downgrade & Very low \\
\hline Arbidol & OR $0.53(0.15,1.87)$ & RCT (high) & No downgrade & No downgrade & No downgrade & No downgrade & No downgrade & High \\
\hline $\begin{array}{l}\text { Lopinavir-Ritonavir plus } \\
\text { interferon-a }\end{array}$ & OR $0.62(0.12,3.20)$ & Observational study (low) & No downgrade & Downgrade* & No downgrade & No downgrade & No downgrade & Very low \\
\hline
\end{tabular}




\begin{tabular}{|c|c|c|c|c|c|c|c|c|}
\hline Hydroxychloroquine & OR $0.84(0.44,1.59)$ & Observational study (low) & No downgrade & No downgrade & No downgrade & No downgrade & No downgrade & Low \\
\hline Arbidol plus Lopinavir- & OR $0.85(0.16,4.52)$ & Observational study (low) & No downgrade & Downgrade* & No downgrade & No downgrade & No downgrade & Very low \\
\hline \multicolumn{9}{|l|}{$\begin{array}{l}\text { Ritonavir plus interferon- } \\
\text { a }\end{array}$} \\
\hline Interferon-a & OR $1.33(0.15,11.79)$ & Observational study (low) & No downgrade & Downgrade* & No downgrade & Downgrade & No downgrade & Very low \\
\hline Lopinavir-Ritonavir & OR $1.23(0.41,3.73)$ & Observational study (low) & No downgrade & No downgrade & No downgrade & No downgrade & No downgrade & Low \\
\hline $\begin{array}{l}\text { Lopinavir-Ritonavir plus } \\
\text { arbidol }\end{array}$ & OR $1.66(0.29,9.55)$ & Observational study (low) & Downgrade & No downgrade & No downgrade & Downgrade & No downgrade & Very low \\
\hline $\begin{array}{l}\text { Hydroxychloroquine plus } \\
\text { azithromycin plus zinc }\end{array}$ & OR $3.08(0.12,81.00)$ & Observational study (low) & No downgrade & Downgrade* & Downgrade & Downgrade & No downgrade & Very low \\
\hline Baloxavir & OR $3.31(0.12,90.72)$ & RCT (high) & No downgrade & Downgrade* & No downgrade & Downgrade & No downgrade & Low \\
\hline Corticosteroid & OR $4.39(0.46,41.41)$ & Observational study (low) & No downgrade & Downgrade* & No downgrade & Downgrade & No downgrade & Very low \\
\hline $\begin{array}{l}\text { Hydroxychloroquine plus } \\
\text { azithromycin }\end{array}$ & $\begin{array}{l}\text { OR } 5.65(0.22, \\
144.76)\end{array}$ & Observational study (low) & No downgrade & No downgrade & No downgrade & Downgrade & No downgrade & Very low \\
\hline Favipiravir & $\begin{array}{l}\text { OR } 6.97(0.29 \\
166.82)\end{array}$ & RCT (high) & No downgrade & Downgrade* & No downgrade & Downgrade & No downgrade & Low \\
\hline $\begin{array}{l}\text { Lopinavir-Ritonavir plus } \\
\text { azithromycin }\end{array}$ & $\begin{array}{l}\text { OR 15.31 (0.29, } \\
797.72)\end{array}$ & Observational study (low) & No downgrade & Downgrade* & Downgrade & Downgrade & No downgrade & Very low \\
\hline \multicolumn{9}{|l|}{ Viral clearance rate } \\
\hline Convalescent plasma & $\begin{array}{l}\text { OR 11.39 (3.91, } \\
33.18)\end{array}$ & RCT (high) & No downgrade & Downgrade* & No downgrade & Downgrade & No downgrade & Low \\
\hline Meplazumab & OR $8.67(1.53,49.22)$ & Observational study (low) & No downgrade & Downgrade* & No downgrade & Downgrade & No downgrade & Very low \\
\hline Hydroxychloroquine & OR $6.08(2.74,13.48)$ & Observational study (low) & No downgrade & No downgrade & No downgrade & No downgrade & No downgrade & Moderate $\neq$ \\
\hline $\begin{array}{l}\text { Lopinavir-Ritonavir plus } \\
\text { arbidol }\end{array}$ & OR $4.29(0.63,29.32)$ & Observational study (low) & Downgrade & No downgrade & Downgrade & Downgrade & No downgrade & Very low \\
\hline $\begin{array}{l}\text { Lopinavir-Ritonavir plus } \\
\text { navaferon }\end{array}$ & OR $1.70(0.34,8.43)$ & Observational study (low) & No downgrade & Downgrade* & Downgrade & Downgrade & No downgrade & Very low \\
\hline Baloxavir & OR $1.50(0.26,8.80)$ & RCT (high) & No downgrade & Downgrade* & No downgrade & Downgrade & No downgrade & Low \\
\hline Navaferon & OR $0.95(0.20,4.59)$ & RCT (high) & No downgrade & Downgrade* & Downgrade & Downgrade & No downgrade & Very low \\
\hline Favipiravir & OR $0.80(0.13,4.87)$ & RCT (high) & No downgrade & Downgrade* & No downgrade & Downgrade & No downgrade & Low \\
\hline Arbidol & OR $0.84(0.26,2.76)$ & RCT (high) & No downgrade & Downgrade* & No downgrade & Downgrade & No downgrade & Low \\
\hline Lopinavir-Ritonavir & OR $0.78(0.24,2.57)$ & RCT (high) & No downgrade & No downgrade & No downgrade & Downgrade & No downgrade & Moderate \\
\hline $\begin{array}{l}\text { High dose } \\
\text { hydroxychloroquine }\end{array}$ & OR $0.58(0.31,1.12)$ & RCT (high) & No downgrade & Downgrade* & No downgrade & No downgrade & No downgrade & Moderate \\
\hline \multicolumn{9}{|l|}{ Time to viral clearance (days) } \\
\hline Meplazumab & $\begin{array}{l}\text { MD -10.00 (-16.93, - } \\
3.07)\end{array}$ & Observational study (low) & No downgrade & Downgrade* & No downgrade & Downgrade & No downgrade & Very low \\
\hline Hydroxychloroquine & $\begin{array}{l}\text { MD -3.84 (-5.78, - } \\
1.90)\end{array}$ & Observational study (low) & No downgrade & No downgrade & No downgrade & No downgrade & No downgrade & Moderate $\ddagger$ \\
\hline Favipiravir & $\begin{array}{l}\text { MD -3.45 (-6.85, - } \\
0.05)\end{array}$ & RCT (high) & No downgrade & Downgrade* & No downgrade & No downgrade & No downgrade & Moderate \\
\hline
\end{tabular}




\begin{tabular}{|c|c|c|c|c|c|c|c|c|}
\hline $\begin{array}{l}\text { Lopinavir-Ritonavir plus } \\
\text { navaferon }\end{array}$ & $\begin{array}{l}\text { MD }-0.28(-3.01, \\
2.45)\end{array}$ & RCT (high) & No downgrade & Downgrade* & Downgrade & No downgrade & No downgrade & Low \\
\hline Oseltamivir & MD $0.15(-2.60,2.90)$ & Observational study (low) & No downgrade & Downgrade* & No downgrade & No downgrade & No downgrade & Very low \\
\hline LMWH & MD $0.28(-9.10,9.66)$ & Observational study (low) & No downgrade & Downgrade* & No downgrade & Downgrade & No downgrade & Very low \\
\hline Navaferon & MD $0.62(-2.10,3.34)$ & RCT (high) & No downgrade & Downgrade* & Downgrade & No downgrade & No downgrade & Low \\
\hline Ruxolitinib & MD $0.72(-5.50,6.93)$ & RCT (high) & No downgrade & Downgrade* & No downgrade & Downgrade & No downgrade & Low \\
\hline $\begin{array}{l}\text { Hydroxychloroquine plus } \\
\text { arbidol }\end{array}$ & $\begin{array}{l}\text { MD 1.26 (-9.55, } \\
12.07)\end{array}$ & Observational study (low) & No downgrade & Downgrade* & No downgrade & Downgrade & No downgrade & Very low \\
\hline $\begin{array}{l}\text { High dose } \\
\text { hydroxychloroquine }\end{array}$ & MD $1.00(-2.57,4.57)$ & RCT (high) & No downgrade & Downgrade* & No downgrade & No downgrade & No downgrade & Moderate \\
\hline Arbidol & MD $1.06(-0.96,3.08)$ & RCT (high) & No downgrade & No downgrade & No downgrade & No downgrade & No downgrade & High \\
\hline Lopinavir-Ritonavir & MD $1.62(-0.29,3.53)$ & RCT (high) & No downgrade & No downgrade & No downgrade & No downgrade & No downgrade & High \\
\hline Baloxavir & $\begin{array}{l}\text { MD } 7.46(-10.10, \\
25.02)\end{array}$ & RCT (high) & No downgrade & Downgrade* & No downgrade & Downgrade & No downgrade & Low \\
\hline Oseltamivir plus arbidol & MD $4.57(-0.42,9.56)$ & Observational study (low) & No downgrade & Downgrade* & No downgrade & No downgrade & No downgrade & Very low \\
\hline $\begin{array}{l}\text { Lopinavir-Ritonavir plus } \\
\text { arbidol }\end{array}$ & MD $4.34(0.80,7.88)$ & Observational study (low) & Downgrade & No downgrade & No downgrade & No downgrade & No downgrade & Very low \\
\hline \multicolumn{9}{|c|}{$\Delta \mathrm{QTc}$ interval from baseline (msec) of HQ plus $\mathrm{AZ}$ and $\mathrm{AZ}$ alone compared to $\Delta \mathrm{QTc}$ of control (HQ alone) } \\
\hline $\begin{array}{l}\text { Hydroxychloroquine plus } \\
\text { azithromycin (vs. HQ) }\end{array}$ & $\begin{array}{l}\text { MD 20.97 (12.60, } \\
28.98)\end{array}$ & Observational study (low) & No downgrade & No downgrade & No downgrade & No downgrade & No downgrade & Low \\
\hline Azithromycin (vs. HQ) & $\begin{array}{l}\text { OR } 4.09(-15.76, \\
23.94)\end{array}$ & Observational study (low) & Downgrade & Downgrade* & Downgrade & Downgrade & No downgrade & Very low \\
\hline \multicolumn{9}{|c|}{ Proportion of patients experiencing QTc prolongation $(>500 \mathrm{~ms}$ or delta $>60 \mathrm{~ms})$} \\
\hline $\begin{array}{l}\text { Hydroxychloroquine plus } \\
\text { azithromycin }\end{array}$ & OR $1.85(1.05,3.26)$ & Observational study (low) & No downgrade & No downgrade & No downgrade & No downgrade & No downgrade & Low \\
\hline $\begin{array}{l}\text { High dose } \\
\text { hydroxychloroquine }\end{array}$ & OR $2.12(0.56,8.07)$ & Observational study (low) & No downgrade & No downgrade & No downgrade & Downgrade & No downgrade & Very low \\
\hline Hydroxychloroquine & OR $1.33(0.78,2.24)$ & Observational study (low) & No downgrade & No downgrade & No downgrade & No downgrade & No downgrade & Low \\
\hline Azithromycin & OR $1.05(0.56,1.97)$ & Observational study (low) & Downgrade & No downgrade & No downgrade & No downgrade & No downgrade & Very low \\
\hline \multicolumn{9}{|c|}{ Fatal cardiac complication after HQ (TdP, cardiac arrest, and severe ventricular arrhythmia) - overall study } \\
\hline $\begin{array}{l}\text { Hydroxychloroquine plus } \\
\text { azithromycin }\end{array}$ & OR $2.25(1.27,3.99)$ & Observational study (low) & No downgrade & No downgrade & No downgrade & No downgrade & No downgrade & Low \\
\hline $\begin{array}{l}\text { High dose } \\
\text { hydroxychloroquine }\end{array}$ & OR $1.95(0.37,10.28)$ & RCT (high) & No downgrade & No downgrade & No downgrade & Downgrade & No downgrade & Moderate \\
\hline Hydroxychloroquine & OR $1.64(0.91,2.97)$ & Observational study (low) & No downgrade & No downgrade & No downgrade & No downgrade & No downgrade & Low \\
\hline Azithromycin & OR $0.59(0.27,1.29)$ & Observational study (low) & No downgrade & No downgrade & No downgrade & Downgrade & No downgrade & Very low \\
\hline \multicolumn{9}{|c|}{ Fatal cardiac complication after HQ (TdP, cardiac arrest, and severe ventricular arrhythmia) - studies with CAD/CHD $<10 \%$ at baseline } \\
\hline Hydroxychloroquine & OR $1.16(0.07,19.00)$ & Observational study (low) & No downgrade & Downgrade* & No downgrade & Do & No & Very low \\
\hline $\begin{array}{l}\text { Hydroxychloroquine plus } \\
\text { azithromycin }\end{array}$ & OR $1.00(0.06,16.89)$ & Observational study (low) & No downgrade & Downgrade* & No downgrade & Downgrade & No downgrade & Very low \\
\hline High dose & OR $1.00(0.14,7.15)$ & RCT (high) & No downgrade & No downgrade & No downgrade & Downgrade & No downgrade & Moderate \\
\hline
\end{tabular}


hydroxychloroquine

\begin{tabular}{|c|c|c|c|c|c|c|c|c|}
\hline $\begin{array}{l}\text { High dose } \\
\text { hydroxychloroquine }\end{array}$ & $\begin{array}{l}\text { OR 9.10 (0.40, } \\
207.87)\end{array}$ & RCT (high) & No downgrade & Downgrade* & No downgrade & Downgrade & No downgrade & Low \\
\hline $\begin{array}{l}\text { Hydroxychloroquine plus } \\
\text { azithromycin }\end{array}$ & OR $2.26(1.26,4.05)$ & Observational study (low) & No downgrade & No downgrade & No downgrade & No downgrade & No downgrade & Low \\
\hline Hydroxychloroquine & OR $1.77(0.96,3.27)$ & Observational study (low) & No downgrade & No downgrade & No downgrade & No downgrade & No downgrade & Low \\
\hline Azithromycin & OR $0.63(0.28,1.41)$ & Observational study (low) & Downgrade & No downgrade & No downgrade & No downgrade & No downgrade & Very low \\
\hline \multicolumn{9}{|c|}{ Non-cardiac serious adverse events } \\
\hline $\begin{array}{l}\text { Lopinavir-Ritonavir plus } \\
\text { interferon plus ribavirin }\end{array}$ & OR $0.08(0.00,2.22)$ & RCT (high) & No downgrade & Downgrade* & Downgrade & Downgrade & No downgrade & Very low \\
\hline Ruxolitinib & OR $0.09(0.00,1.89)$ & RCT (high) & No downgrade & Downgrade* & No downgrade & Downgrade & No downgrade & Low \\
\hline $\begin{array}{l}\text { Short-term used } \\
\text { remdesivir }\end{array}$ & OR $0.36(0.21,0.60)$ & RCT (high) & No downgrade & Downgrade* & Downgrade & No downgrade & No downgrade & Low \\
\hline Lopinavir-Ritonavir & OR $0.53(0.28,1.02)$ & RCT (high) & No downgrade & No downgrade & No downgrade & No downgrade & No downgrade & High \\
\hline $\begin{array}{l}\text { Lopinavir-Ritonavir plus } \\
\text { navaferon }\end{array}$ & OR $0.53(0.03,9.60)$ & RCT (high) & No downgrade & No downgrade & Downgrade & Downgrade & No downgrade & Low \\
\hline Navaferon & OR $0.53(0.03,9.60)$ & RCT (high) & No downgrade & No downgrade & Downgrade & Downgrade & No downgrade & Low \\
\hline Meplazumab & OR $0.63(0.04,11.16)$ & Observational study (low) & No downgrade & Downgrade* & No downgrade & Downgrade & No downgrade & Very low \\
\hline Remdesivir & OR $0.71(0.55,0.92)$ & RCT (high) & No downgrade & No downgrade & No downgrade & No downgrade & No downgrade & High \\
\hline Hydroxychloroquine & OR $0.73(0.30,1.80)$ & Observational study (low) & Downgrade & No downgrade & No downgrade & No downgrade & No downgrade & Very low \\
\hline Baloxavir & OR $1.00(0.06,16.76)$ & RCT (high) & No downgrade & No downgrade & No downgrade & Downgrade & No downgrade & Moderate \\
\hline Favipiravir & OR $1.00(0.06,16.76)$ & RCT (high) & No downgrade & No downgrade & No downgrade & Downgrade & No downgrade & Moderate \\
\hline a-Lipoic acid & OR $1.00(0.06,16.76)$ & RCT (high) & No downgrade & Downgrade* & No downgrade & Downgrade & No downgrade & Low \\
\hline $\begin{array}{l}\text { Hydroxychloroquine plus } \\
\text { azithromycin }\end{array}$ & OR $1.00(0.13,7.58)$ & Observational study (low) & No downgrade & No downgrade & No downgrade & Downgrade & No downgrade & Very low \\
\hline $\begin{array}{l}\text { High dose } \\
\text { hydroxychloroquine }\end{array}$ & OR $2.30(1.01,5.22)$ & RCT (high) & No downgrade & No downgrade & No downgrade & Downgrade & No downgrade & Moderate \\
\hline Convalescent plasma & $\begin{array}{l}\text { OR } 5.10(0.24, \\
108.86)\end{array}$ & RCT (high) & No downgrade & Downgrade* & No downgrade & Downgrade & No downgrade & Low \\
\hline
\end{tabular}

OR: odds ratio. MD: mean difference. CAD: coronary artery disease. CHD: congestive heart disease.

*: downgraded by one when unable to evaluate inconsistency/heterogeneity due to lack of sufficient data (a single study). łupgrade by one for dose-response gradient

Rationale:

Study design: If randomized trials form the evidence base, the quality rating starts at "high". If observational studies form the evidence, base the quality rating starts at "low".

Risk of bias: Downgraded for failure to conceal random allocation or blind participants in randomized controlled trials or failure to adequately control for confounding in observational studies.

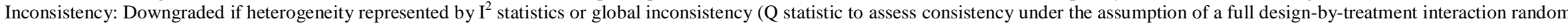
effects model) was high.

Indirectness. Downgraded when assumption of transitivity is challenged, or the result is solely derived from indirect comparisons.

Imprecision: Downgraded when confidential interval (CI) is too large.

Publication bias: Downgraded when substantial asymmetry is observed in funnel plot or $\mathrm{p}<0.05$ in egger's test. 
GRADE Definition (suggested by Puhan et al. in "A GRADE Working Group approach for rating the quality of treatment effect estimates from network meta-analysis"): High quality: We are very confident that the true effect lies close to that of the estimate of the effect.

Moderate quality: We are moderately confident in the effect estimate i.e. the true effect is likely to be close to the estimate of the effect, but there is a possibility that it is substantially different.

Low quality: Our confidence in the effect estimate is limited i.e. the true effect may be substantially different from the estimate of the effect.

Very low quality: We have very little confidence in the effect estimate i.e. the true effect is likely to be substantially different from the estimate of effect. 


\begin{tabular}{|c|c|}
\hline $\begin{array}{l}\text { Potentially relevant studies identified and } \\
\text { retrieved: } n=2702 \\
\text { Additional records identified through pre- } \\
\text { print sources: } n=3268\end{array}$ & \\
\hline & $\begin{array}{l}\text { Duplicates and studies unrelated to the } \\
\text { topic: } n=2344\end{array}$ \\
\hline $\begin{array}{l}\text { Title and abstract reviewed: } \\
n=3626\end{array}$ & $\begin{array}{l}\text { Excluded: } n=3375 \\
\text { Case-series, brief report, correspondence }\end{array}$ \\
\hline $\begin{array}{l}\text { Records selected for full test review: } \\
n=251\end{array}$ & $\begin{array}{l}\text { Published before 2020: } n=2011 \\
\text { Trials in children and adolescents: } n=8 \\
\text { Studies without control: } n=121 \\
\text { Other publications from the same } \\
\text { cohort: } \quad n=103\end{array}$ \\
\hline & $\begin{array}{l}\text { Excluded: } n=202 \\
\text { Studies do not present proper statistical data required } \\
\text { for network meta-analysis: } n=36 \\
\text { Significant difference in timing of initiation of } \\
\text { treatment after symptom onset between groups: } n=3 \\
\text { No standardized diagnosis of COVID-19: } n=2 \\
\text { Significant differences in clinically important } \\
\text { baseline characteristics (including severity indices) } \\
\text { between groups without adjustment: } n=49 \\
\text { Initiation of treatment before the diagnosis of } \\
\text { COVID-19 (i.e. ACEi/ARB): } n=18 \\
\text { Systematic review or meta-analysis: } n=27 \\
\text { Absence of outcomes of interest: } n=54 \\
\text { No sufficient information on baseline differences: } n= \\
13\end{array}$ \\
\hline \multicolumn{2}{|c|}{$\begin{array}{l}\text { Randomized controlled trials ( } 16 \text { studies) and baseline-controlled* observational studies ( } 33 \text { studies) } \\
\text { included for network meta-analysis: } n=49 \text { ( } 25 \text { published and } 24 \text { unpublished studies) } \\
\text { *Differences in relevant baseline characteristics between groups were controlled through propensity } \\
\text { score matching (PSM), inverse proportional treatment weighting (IPTW), or adjust regression model. } \\
\text { Studies providing evidence that the risk for such confounding was low by establishing baseline } \\
\text { similarity between the groups also met inclusion criteria. Observational studies presenting crude } \\
\text { (unadjusted) results or derived conclusions from uncontrolled populations were excluded. }\end{array}$} \\
\hline
\end{tabular}

Figure 1. PRISMA diagram showing selection of articles for pairwise and network metaanalysis 
medRxiv preprint doi: https://doi.org/10.1101/2020.06.15.20132407; this version posted June 19, 2020. The copyright holder for this preprint (which was not certified by peer review) is the author/funder, who has granted medRxiv a license to display the preprint in perpetuity. It is made available under a CC-BY-NC-ND 4.0 International license

A Mortality for moderate-severe COVID-19 patients (non-ICU at admission)

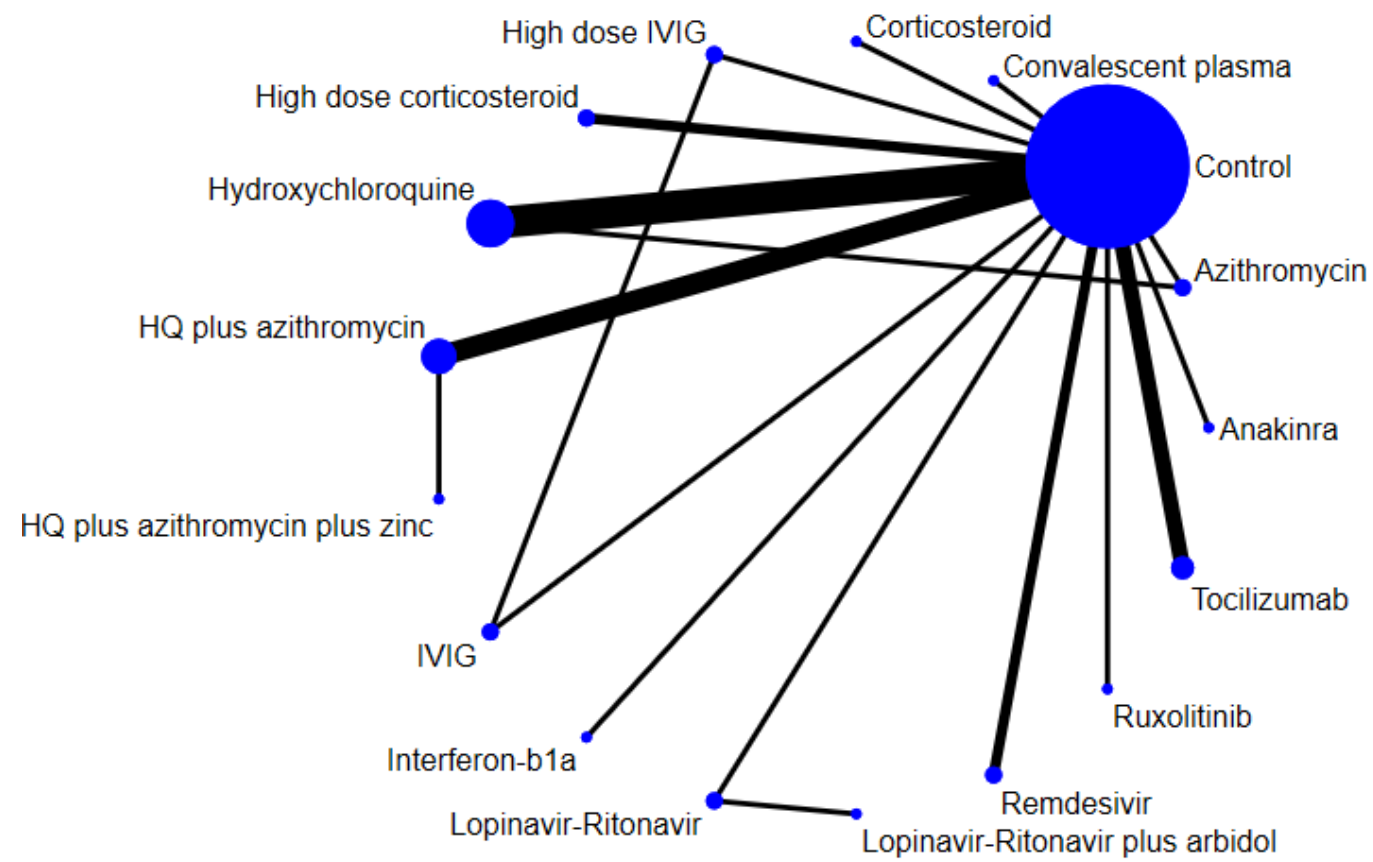

B Mortality for critically ill patients (ICU)

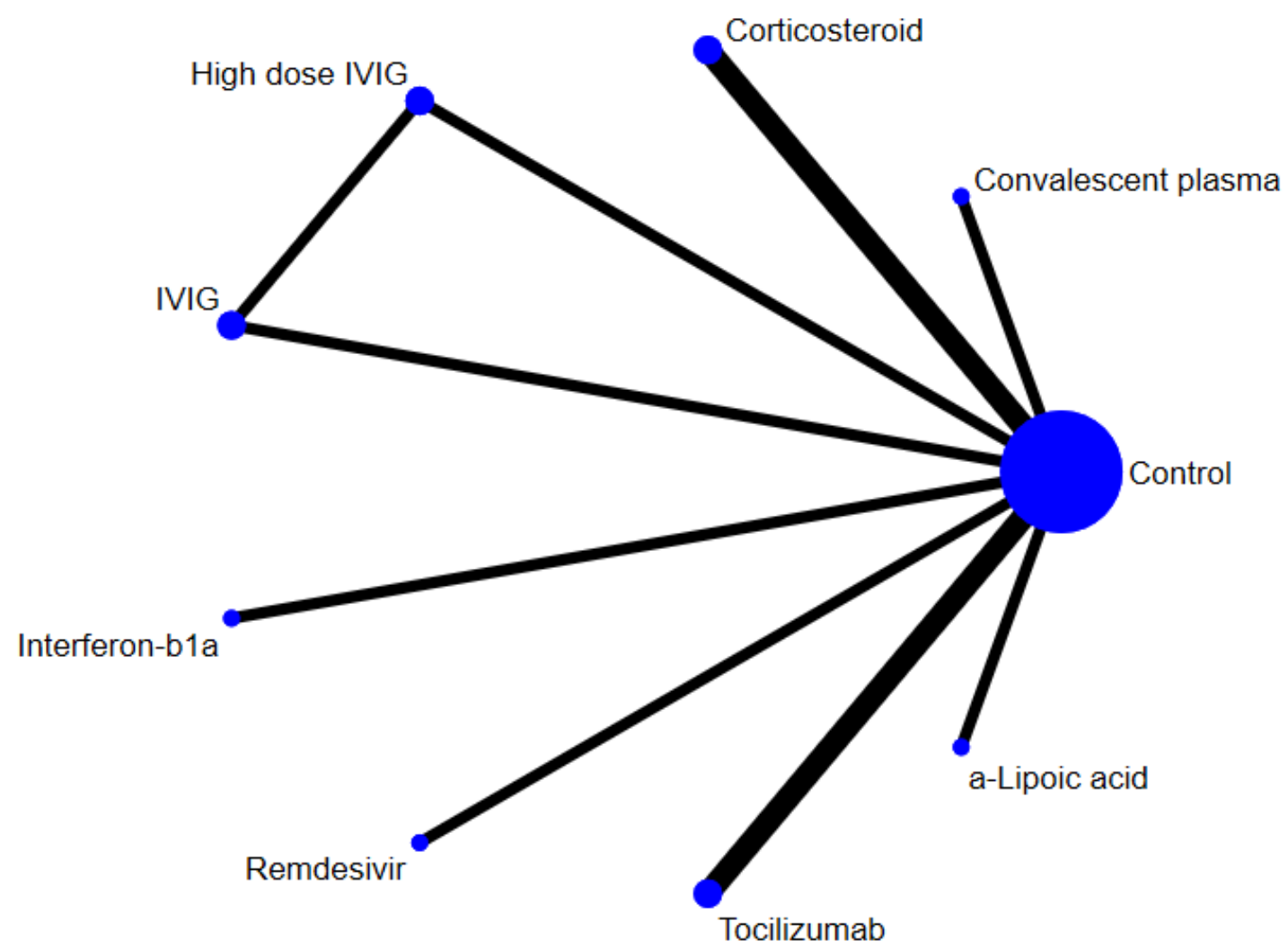


medRxiv preprint doi: https://doi.org/10.1101/2020.06.15.20132407; this version posted June 19, 2020. The copyright holder for this preprin (which was not certified by peer review) is the author/funder, who has granted medRxiv a license to display the preprint in perpetuity. It is made available under a CC-BY-NC-ND 4.0 International license.

C Progression of disease to severe courses (i.e. progression to severe pneumonia and/or admission to ICU)

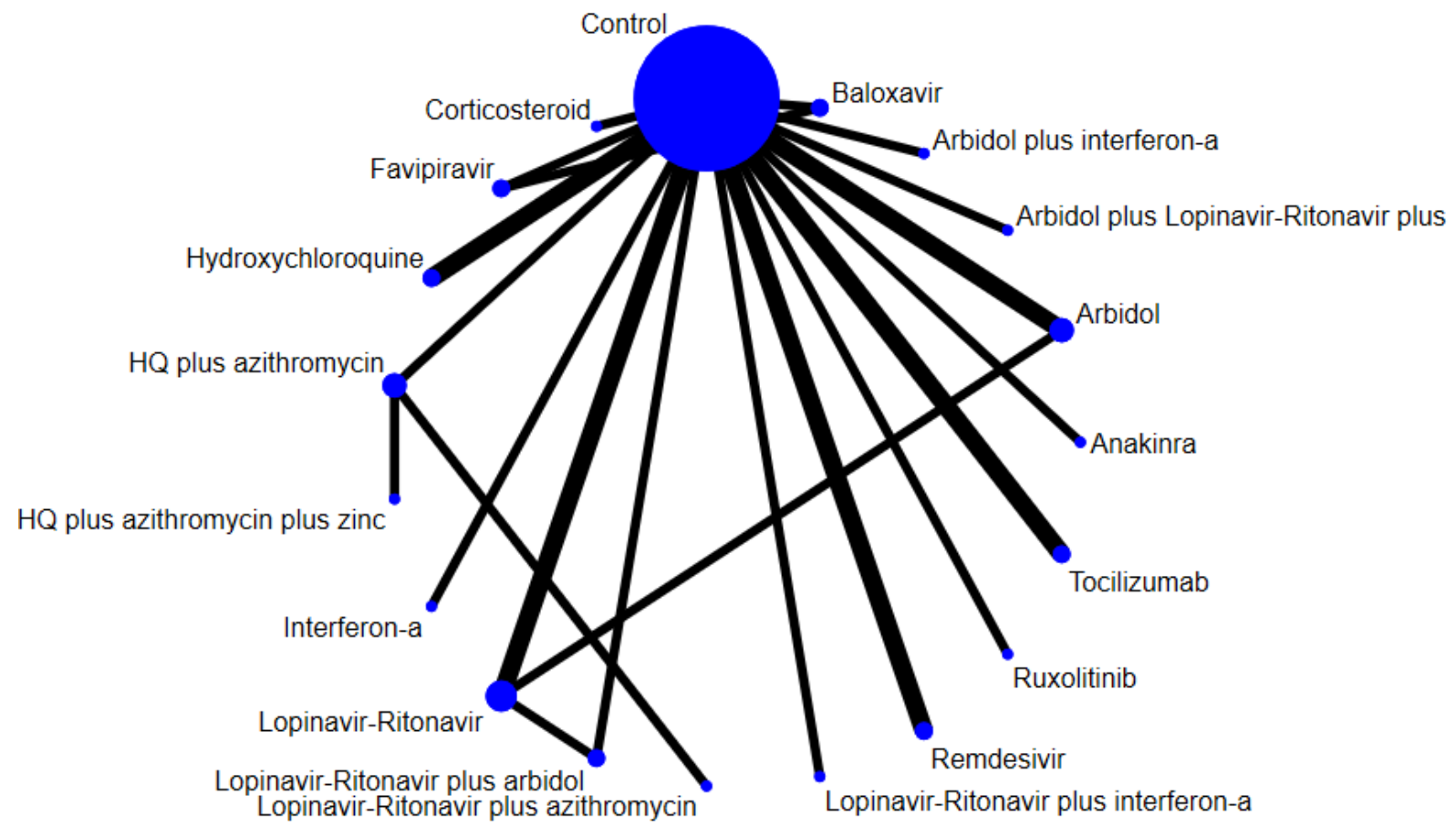

D Time to viral clearance (days)

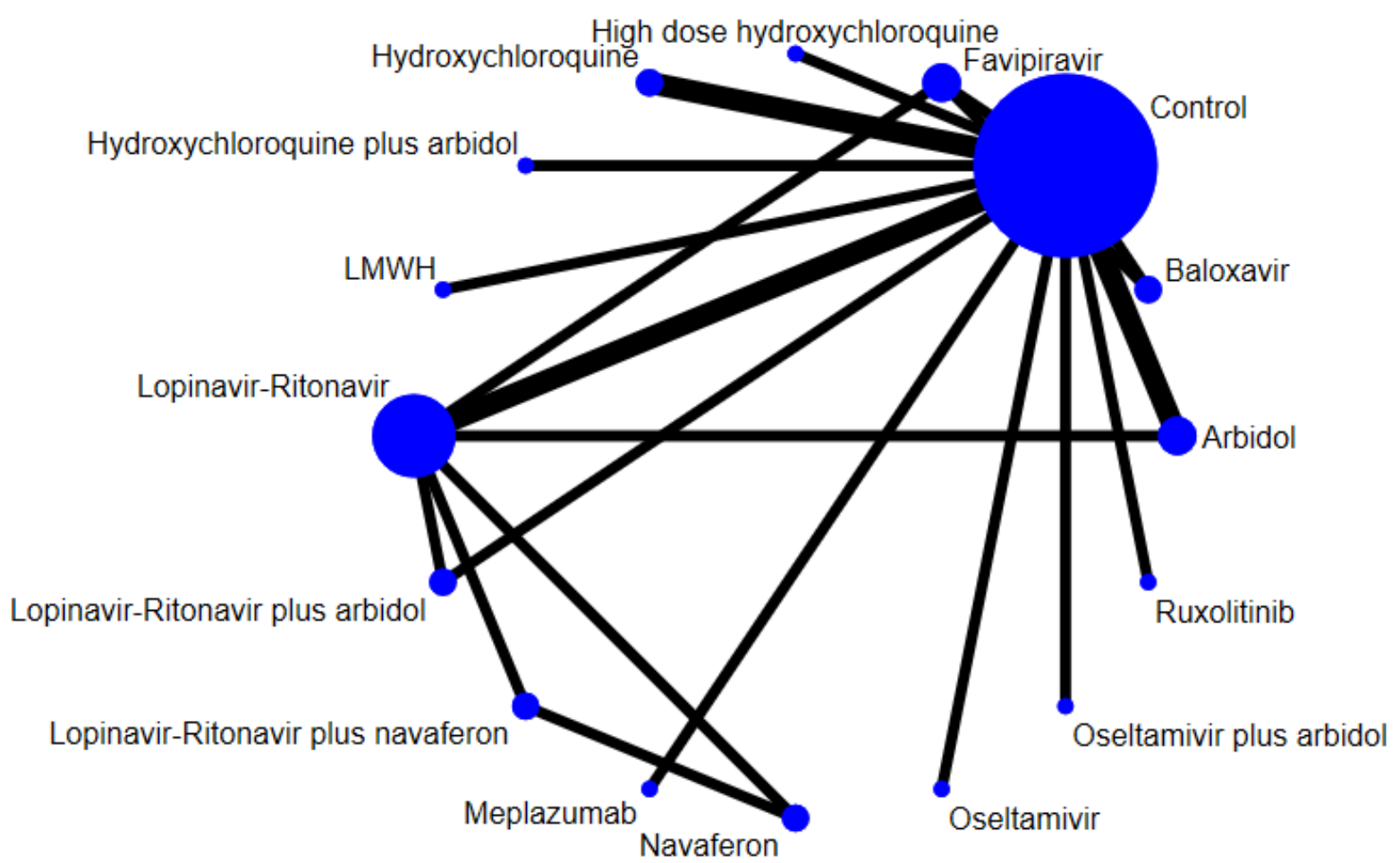


medRxiv preprint doi: https://doi.org/10.1101/2020.06.15.20132407; this version posted June 19, 2020. The copyright holder for this preprin (which was not certified by peer review) is the author/funder, who has granted medRxiv a license to display the preprint in perpetuity. It is made available under a CC-BY-NC-ND 4.0 International license.

E Fatal cardiac adverse event

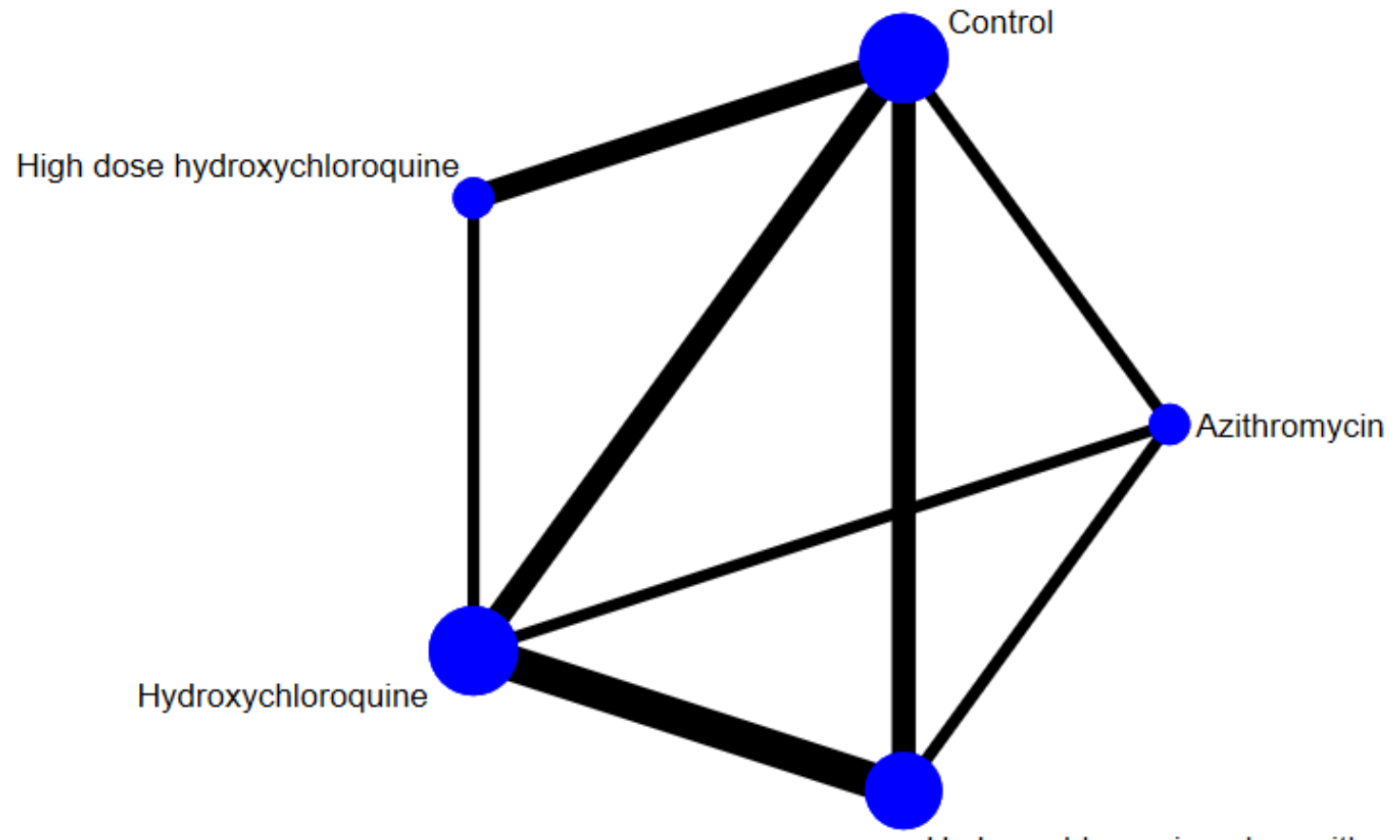

Hydroxychloroquine plus azithromycin

F Non-cardiac serious adverse event

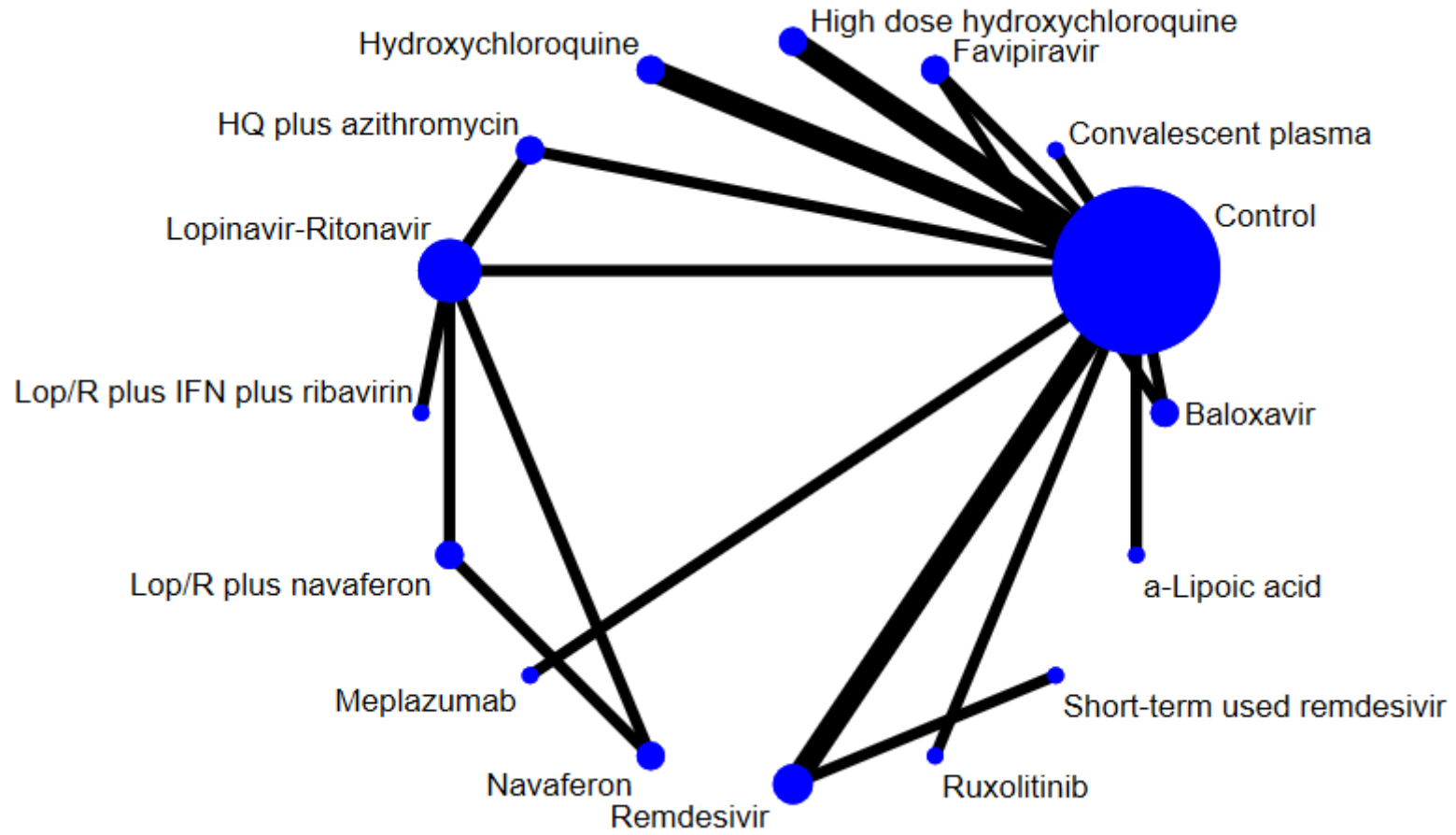

Figure 2: Network of eligible comparisons for primary outcomes

(A) Mortality for moderate-severe COVID-19 patients (non-ICU at admission). (B) mortality 
for critically ill patients (ICU). (C) Progression of disease to severe courses (i.e. progression to severe pneumonia and/or admission to ICU). (D) Time to viral clearance (days). (E) Fatal cardiac adverse events (torsades de pointes, cardiac arrest, and severe ventricular arrhythmia). (F) Non-cardiac serious adverse events. Lines indicate direct comparison of agents, and the thickness of line corresponds to the number of trials in the comparison. Size of node corresponds to the number of studies that involve the intervention. $\mathrm{HQ}=$ Hydroxychloroquine. Lop/R = Lopinavir-Ritonavir. ICU = intensive care unit. 
A Mortality for moderate-severe patients (non-ICU at admission) - all studies

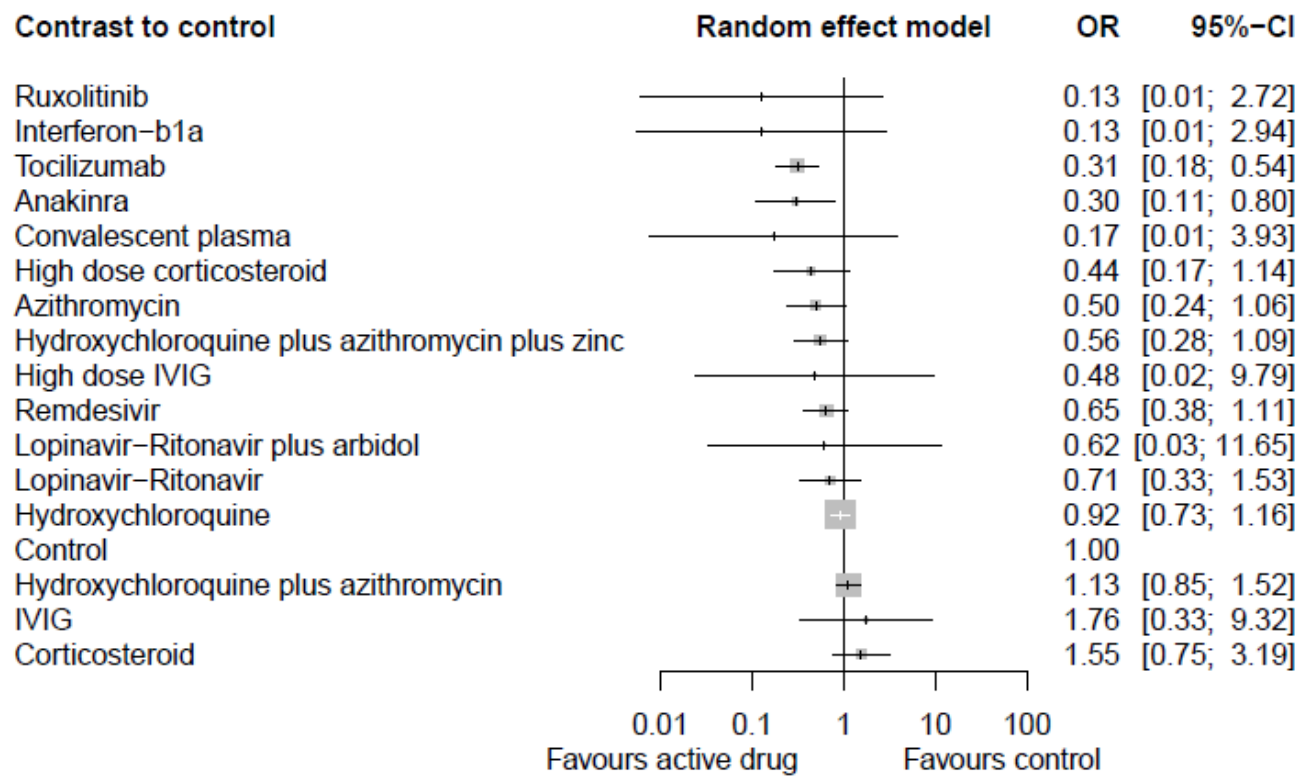

B Mortality for moderate-severe patients (non-ICU at admission) - RCTs only

Contrast to control Random effect model OR $\quad 95 \%-\mathrm{Cl}$

Ruxolitinib

Interferon-b1a

Convalescent plasma

Remdesivir

Lopinavir-Ritonavir

Control

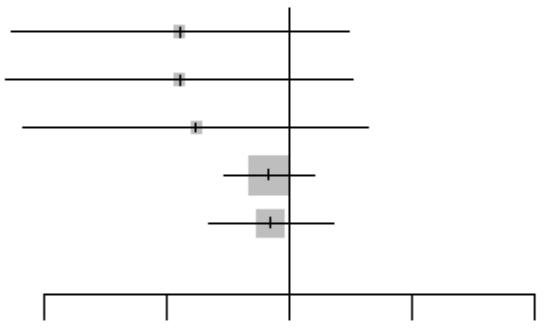

$0.13[0.01 ; 3.10]$

$0.13[0.00 ; 3.34]$

$0.17[0.01 ; 4.46]$

$0.68[0.30 ; 1.58]$

$0.71[0.22 ; 2.31]$

1.00

$\begin{array}{lllll}0.01 & 0.1 & 1 & 10 & 100\end{array}$

Favours active drug Favours control

C Mortality for critically ill patients (ICU) - all studies

Contrast to control Random effect model

OR $\quad 95 \%-\mathrm{Cl}$

High dose IVIG

a-Lipoic acid

Interferon-b1a

Tocilizumab

Convalescent plasma

IVIG

Remdesivir

Control

Corticosteroid

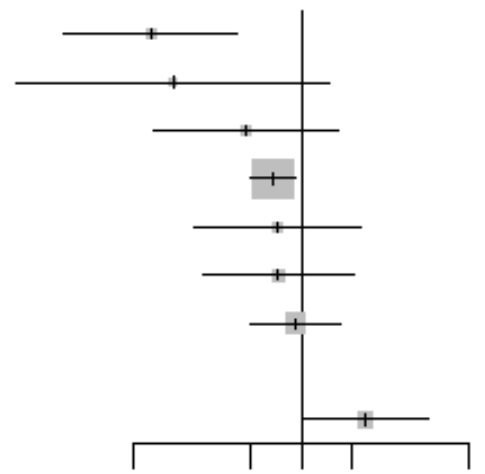

$0.13[0.04 ; 0.42]$

$0.17[0.02 ; 1.46]$

$0.47[0.13 ; 1.65]$

$0.67[0.50 ; 0.91]$

$0.72[0.23 ; 2.29]$

$0.73[0.26 ; 2.02]$

$0.92[0.50 ; 1.69]$

1.00

$2.40[1.02 ; 5.61]$

$\begin{array}{llll}0.1 & 0.51 & 2 & 10\end{array}$

Favours active drug Favours control 
D Mortality for critically ill patients (ICU) - RCTs only

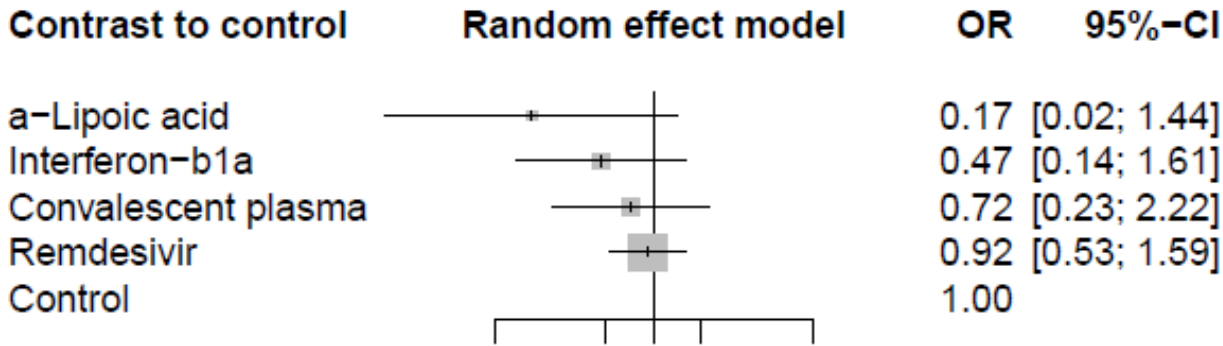

$0.1 \quad 0.512 \quad 10$

Favours active drug Favours control

E. Progression to severe course (i.e. progression to severe pneumonia and/or admission to ICU) - all studies

Contrast to control
Ruxolitinib
Anakinra
Remdesivir
Tocilizumab
Arbidol plus interferon-a
Arbidol
Lopinavir-Ritonavir plus interferon-a
Hydroxychloroquine
Arbidol plus Lopinavir-Ritonavir plus interferon-a
Control
Interferon-a
Lopinavir-Ritonavir
Lopinavir-Ritonavir plus arbidol
Hydroxychloroquine plus azithromycin plus zinc
Baloxavir
Corticosteroid
Hydroxychloroquine plus azithromycin
Favipiravir
Lopinavir-Ritonavir plus azithromycin

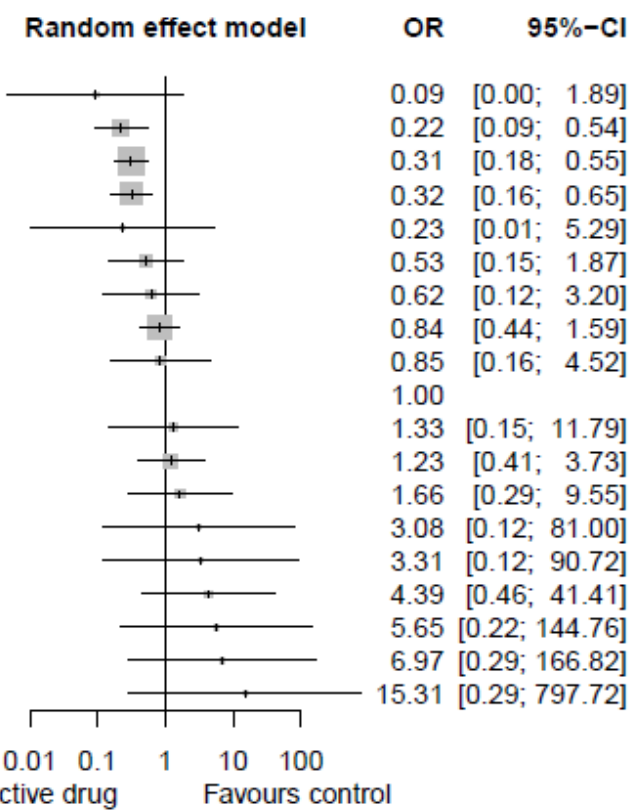

F. Progression to severe course (i.e. progression to severe pneumonia and/or admission to ICU) - RCTs only

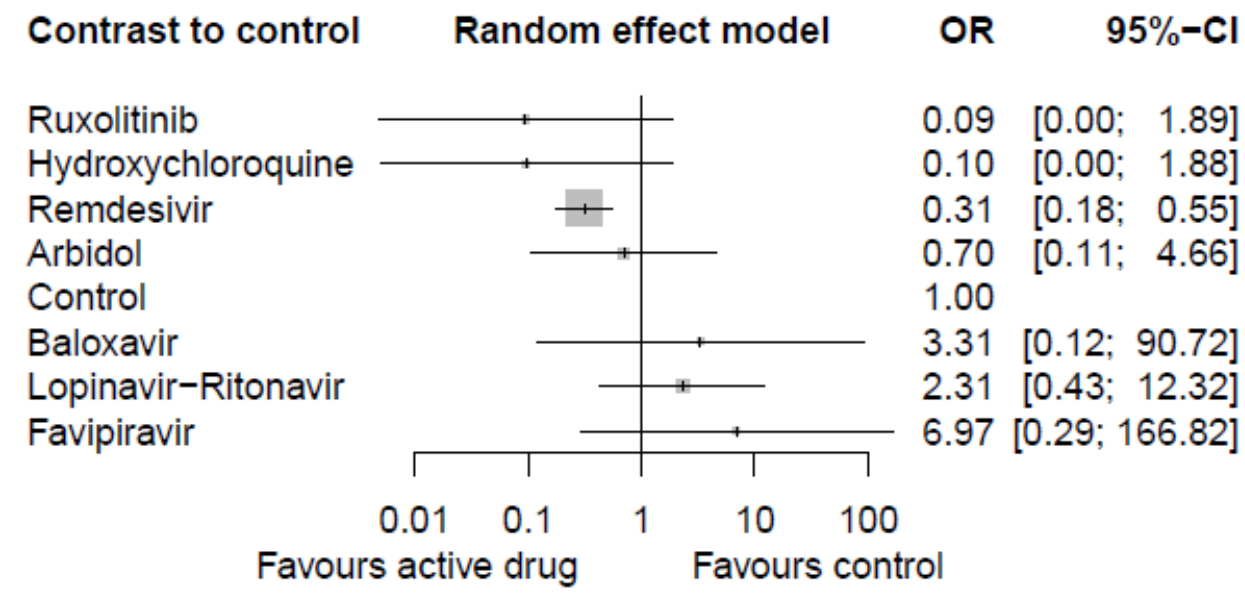


Figure 3: Network meta-analysis of pharmacological interventions compared with control (standard care) for efficacy outcomes.

Mortality for moderate-severe patients (non-ICU at admission) from (A) all studies and (B) RCTs only. Mortality for critically ill patients (ICU) from (C) all studies and (D) RCTs only. Progression to severe course (i.e. progression to severe pneumonia and/or admission to ICU) from (E) all studies and (F) RCTs only. Effect estimates are presented in odds ratios (OR) with 95\% CI. Pharmacological agents are ranked by surface under the cumulative ranking curve $(\mathrm{SUCRA})$ value. $\mathrm{RCT}=$ randomized controlled trial. $\mathrm{ICU}=$ intensive care unit. 
medRxiv preprint doi: https://doi.org/10.1101/2020.06.15.20132407; this version posted June 19, 2020. The copyright holder for this preprint (which was not certified by peer review) is the author/funder, who has granted medRxiv a license to display the preprint in perpetuity. It is made available under a CC-BY-NC-ND 4.0 International license.

A Viral clearance rate - all studies

Contrast to control

Convalescent plasma

Meplazumab

Hydroxychloroquine

Lopinavir-Ritonavir plus arbidol

Lopinavir-Ritonavir plus navaferon

Baloxavir

Control

Navaferon

Favipiravir

Arbidol

Lopinavir-Ritonavir

high dose hydroxychloroquine
Random effect model

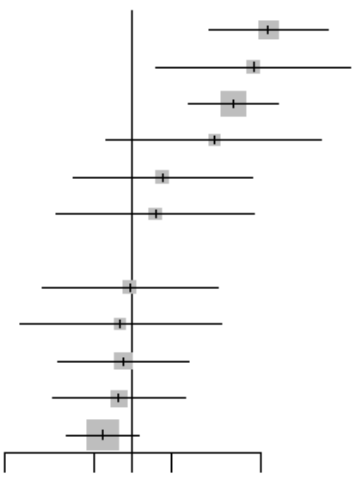

$11.39[3.91 ; 33.18]$

$8.67[1.53 ; 49.22]$

$6.08[2.74 ; 13.48]$

$4.29[0.63 ; 29.32]$

$1.70[0.34 ; 8.43]$

$1.50[0.26 ; 8.80]$

1.00

$0.95[0.20 ; 4.59]$

$0.80[0.13 ; 4.87]$

$0.84[0.26 ; 2.76]$

$0.78[0.24 ; 2.57]$

$0.58[0.31 ; 1.12]$

$\begin{array}{llll}0.1 & 0.512 & 10\end{array}$

Favours control Favours active drug

B Viral clearance rate - RCTs only

\section{Contrast to control}

Convalescent plasma

Lopinavir-Ritonavir plus navaferon

Baloxavir

Control

Navaferon

Arbidol

Favipiravir

Lopinavir-Ritonavir

high dose hydroxychloroquine
Random effect model

OR $\quad 95 \%-\mathrm{Cl}$

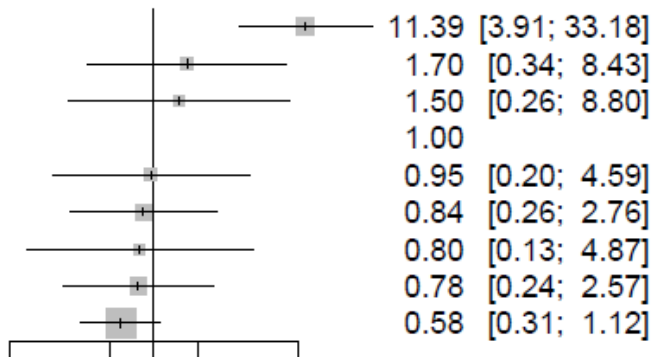

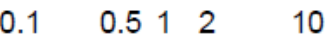

Favours control Favours active drug

C Time to viral clearance (days) - all studies

\section{Contrast to control}

\section{Meplazumab}

Hydroxychloroquine

Favipiravir

Lopinavir-Ritonavir plus navaferon

Control

Oseltamivir

LMWH

Navaferon

Ruxolitinib

Hydroxychloroquine plus arbidol

High dose hydroxychloroquine

Arbidol

Lopinavir-Ritonavir

Baloxavir

Oseltamivir plus arbidol

Lopinavir-Ritonavir plus arbidol

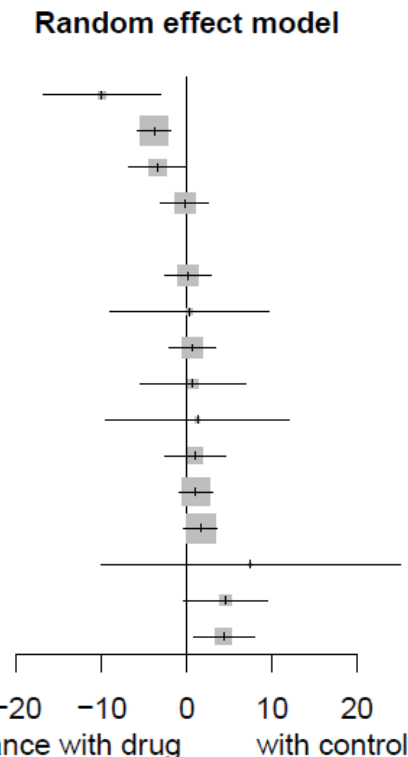

shorter time to viral clearance with drug

\section{MD $\quad 95 \%-\mathrm{Cl}$}

$-10.00[-16.93 ;-3.07]$

$-3.84[-5.78 ;-1.90]$

$-3.45[-6.85 ;-0.05]$

$-0.28 \quad[-3.01 ; 2.45]$

0.00

$0.15 \quad[-2.60 ; 2.90]$

$0.28 \quad[-9.10 ; 9.66]$

$0.62 \quad[-2.10 ; 3.34]$

$0.72[-5.50 ; 6.93]$

$1.26[-9.55 ; 12.07]$

$1.00 \quad[-2.57 ; 4.57]$

$1.06 \quad[-0.96 ; 3.08]$

$1.62[-0.29 ; 3.53]$

$7.46[-10.10 ; 25.02]$

$4.57 \quad[-0.42 ; 9.56]$

$4.34 \quad[0.80 ; 7.88]$ 
D Time to viral clearance (days) - RCTs only

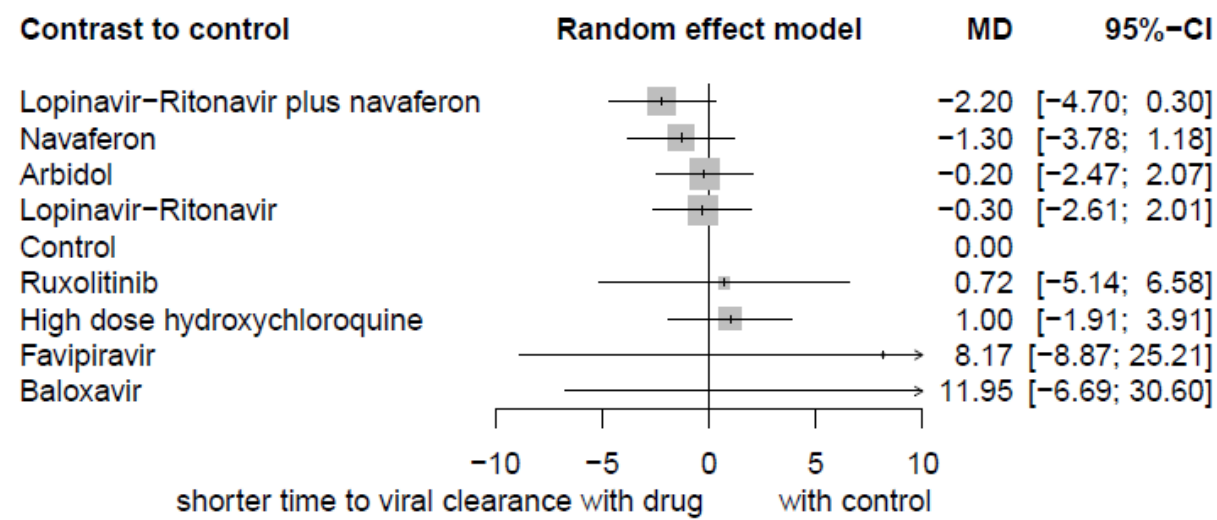

E Time to viral clearance from different initiation timings

$\begin{aligned} & \text { Initiation of } \\ & \text { treatment after onset }\end{aligned}$
$\begin{array}{r}\left(\begin{array}{r}\text { Mean differen } \mathrm{Cl}) \text { in time to vinas } \\ \text { clearance compar } \\ \text { to standard ca }\end{array}\right. \\ \text { <3days } \\ \text { 3-14days }\end{array}$
$>$ >14days

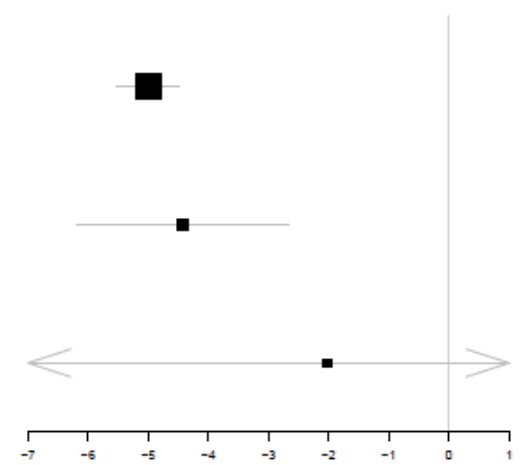

Figure 4: Network meta-analysis of pharmacological interventions compared with control (standard care) for viral clearance.

Viral clearance rate (proportion of patients converted to PCR-negative status) from (A) all studies and (B) RCTs only. Time to viral clearance (days) from (C) all studies and (D) RCTs only. (E) Time to viral clearance from different hydroxychloroquine treatment initiation timings after symptom onset. Effect estimates are presented in odds ratios (OR) for viral clearance rate and mean differences (MD) for time to viral clearance, with $95 \%$ CI. Pharmacological agents are ranked by surface under the cumulative ranking curve (SUCRA) value. $\mathrm{RCT}=$ randomized controlled trial. 
A Change in QTc interval from baseline (msec)

\section{Contrast to Hydroxychloroquine}

Hydroxychloroquine plus azithromycin Azithromycin

Hydroxychloroquine

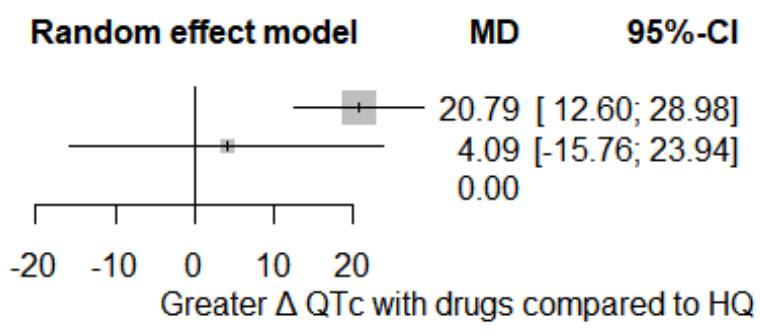

B Proportion of patients experiencing QTc prolongation

\section{Contrast to control}

Hydroxychloroquine plus azithromycin High dose hydroxychloroquine Hydroxychloroquine Azithromycin Control

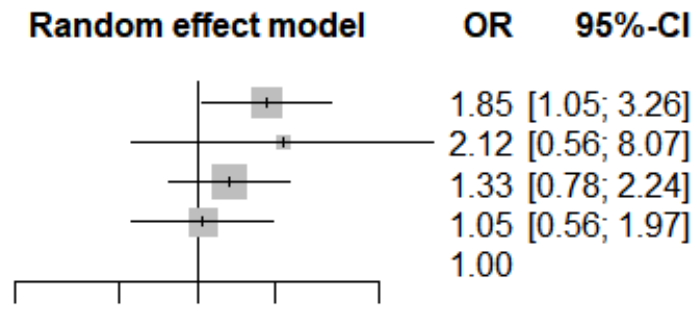

$\begin{array}{lllll}0.2 & 0.5 & 1 & 2 & 5\end{array}$

Favours control QTc prolongation with active drug

C Fatal cardiac complications

Study

\section{Overall study}

Hydroxychloroquine plus azithromycin High dose hydroxychloroquine Hydroxychloroquine

Control

Azithromycin

Studies with CAD/CHD $<10 \%$ at baseline

Hydroxychloroquine

Hydroxychloroquine plus azithromycin

High dose hydroxychloroquine

Control

\section{Studies with CAD/CHD $>10 \%$ at baseline}

High dose hydroxychloroquine

Hydroxychloroquine plus azithromycin

Hydroxychloroquine

Control

Azithromycin
Odds Ratio

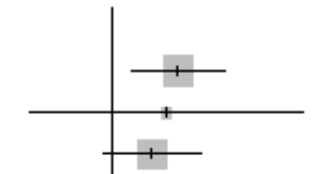

$2.25 \quad[1.27 ; 3.99]$

$1.95[0.37 ; 10.28]$

$1.64 \quad[0.91 ; 2.97]$

1.00

$0.59 \quad[0.27 ; 1.29]$

D Non-cardiac serious adverse events 


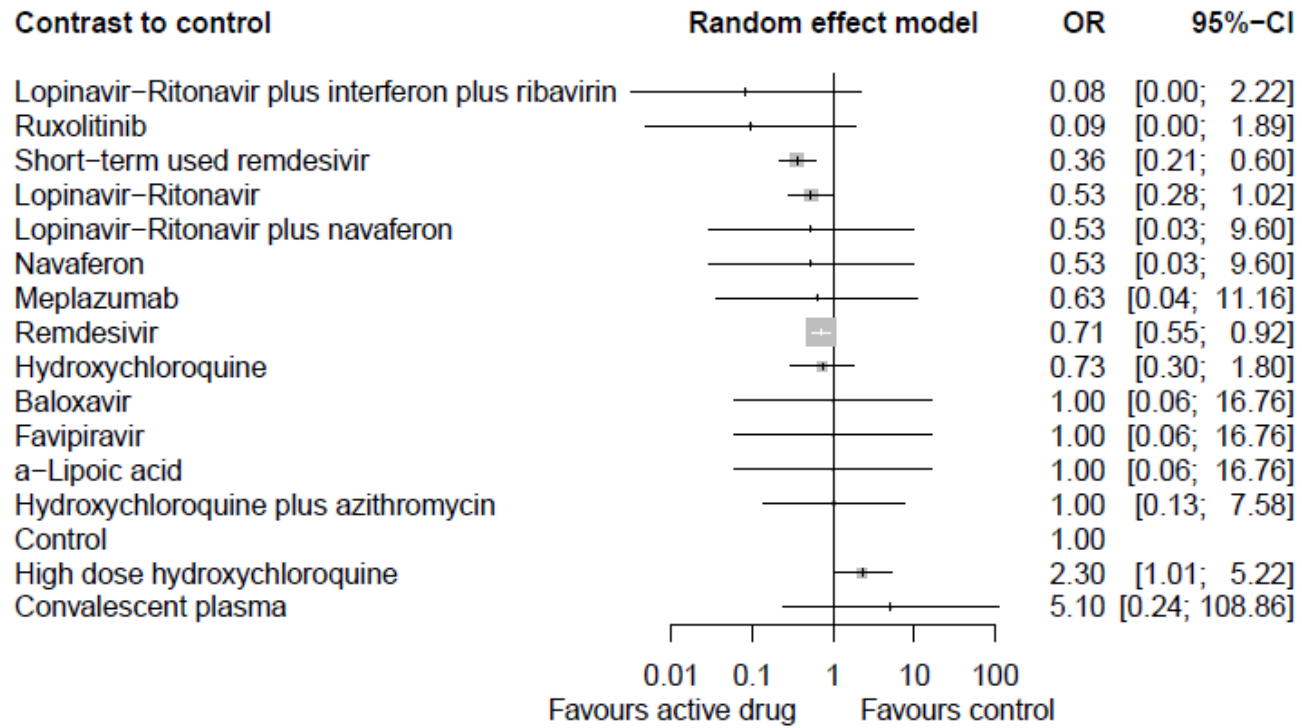

Figure 5: Network meta-analysis of safety of different pharmacological interventions.

(A) Change in QTc interval $(\triangle \mathrm{QTc})$ from baseline (msec). (B) Proportion of patients experiencing QTc prolongation ( $>500 \mathrm{~ms}$ or $\Delta$ QTc $>60 \mathrm{~ms}$ ). (C) Fatal cardiac complication after hydroxychloroquine administration (torsades de pointes, cardiac arrest, and severe ventricular arrhythmia). (D) Non-cardiac serious adverse events. Effect estimates are presented in odds ratios (OR) and mean differences (MD) with 95\% CI. Pharmacological agents are ranked by surface under the cumulative ranking curve (SUCRA) value. CAD = coronary artery disease. $\mathrm{CHD}=$ congestive heart disease. $\mathrm{HQ}=$ hydroxychloroquine. 